\title{
Bonnie McLean* \\ Revising an implicational hierarchy for the meanings of ideophones, with special reference to Japonic
}

\author{
https://doi.org/10.1515/lingty-2020-2063
}

Received October 17, 2019; accepted August 8, 2020; published online October 19, 2020

\begin{abstract}
An elicitation task was conducted with speakers of Japonic varieties to investigate whether stimuli of varying sensory modalities (e.g. audio, visual, tactile etc.) were more or less likely to elicit ideophones or iconic words. Stimuli representing sounds, movements, shapes and textures were most likely to elicit ideophones, and this is posited to reflect the relative ease or naturalness with which these domains can be mapped iconically to speech. The results mirror macro-level patterns of linguistic diversity, as these are also domains in which ideophones are most widely attested cross-linguistically. The findings call for the revision of a previously constructed implicational hierarchy for the semantic development of ideophone systems, adding to it the categories of FORM and TEXTURE as domains in which ideophones are most likely to develop, after SOUND and MOVEMENT. Independent evidence for the revised hierarchy comes from a semantic analysis of the elicited ideophones, where it was found that domains early in the hierarchy were more likely to be sources for semantic extension, while later domains were more likely to be targets. These findings are expected to be replicable for other languages, and offer exciting new directions for research into the semantic typology of ideophones.
\end{abstract}

Keywords: ideophones, iconicity, sensory language, semantic typology, implicational hierarchies, semantic maps, Japanese, Ryukyuan

\section{Introduction}

In linguistic typology, the term ideophone refers to 'a member of an open lexical class of marked words that depict sensory imagery' (Dingemanse 2019; see also Blench 2010; Diffloth 1972; Hinton et al. 1994). As depictive words, ideophones are prototypically iconic, meaning that there is a perceived resemblance between

*Corresponding author: Bonnie McLean ['boni mə'kleın], Uppsala University, Box 635, 75126 Uppsala, Sweden, E-mail: bonnie.mclean@lingfil.uu.se 
aspects of their form and meaning. However, this iconicity is rarely fully transparent, and ideophones also rely on convention to function as fully-fledged words in the linguistic systems of individual languages. Examples of ideophones in Japanese are saa 'the sound of rain', taratara 'trickling', tsuntsun 'pointy', fuwafuwa 'fluffy', and hirahira 'thrilled'.

As these examples demonstrate, the meanings of ideophones cover a broad range of semantic domains. However, their reference is also constrained in certain ways by their iconicity. Since they use perceptuomotor analogies to connect form with meaning, ideophones tend to refer to things that we can directly perceive with our senses, rather than to abstract concepts (Dingemanse 2012; Lupyan and Winter 2018). It has also been proposed that the semantic development of ideophone lexicons follows a cross-linguistically constrained implicational hierarchy (Dingemanse 2012; see also Akita 2013; Van Hoey and Lu in prep.), motivated by the ease with which different sensory domains can be iconically mapped to speech. The original version of the hierarchy developed by Dingemanse (2012) is shown in Figure 1.

The implicational hierarchy predicts that languages develop ideophones first in the domain of sound, next in the domain of movement, then visual patterns, other sensory perceptions, and finally inner feelings and cognitive states. It is used to account for marked distributional patterns in the semantic structure of ideophone lexicons; we can find some languages with ideophones depicting only sound, other languages where ideophones depict movement and sound, but no language with ideophones for movement that lacks ideophones for sound, nor any language with ideophones for a wider variety of sensory perceptions that lacks ideophones for movement and sound, etc. (Dingemanse 2012: 663).

By comparison, the codability of the senses in non-iconic language is highly variable (e.g. Majid et al. 2018). However, we might hypothesise that because they are motivated, form-meaning mappings in iconic lexicons are more constrained by the limitations of their medium, creating this uniformity. This would explain why SOUND, being the simplest iconic mapping from speech, forms the base of the hierarchy for ideophones-even though vision is more salient cross-linguistically (San Roque et al. 2015; Viberg 1983). Movement follows because it is closely connected to sound in perceptual experience, making it another natural domain to

\section{SOUND $<$ MOVEMENT $<$ VISUAL PATTERNS $<$ OTHER SENSORY PERCEPTIONS $<$ INNER FEELINGS AND COGNITIVE STATES}

Figure 1: Implicational hierarchy for the semantic development of ideophone systems proposed by Dingemanse (2012). 
depict with speech sounds. It also lends itself well to depictions involving articulatory gestures (where the movements of the tongue and lips are mapped to the movements of depicted objects) and structural iconicity (where word structure is mapped to event structure) (for more on this see e.g. Diffloth 1972: 444; Dingemanse 2012: 659; Nuckolls 1996; Thompson and Do 2019). Ideophones for other visual perceptions are predicted to appear next, followed by ideophones depicting other sensory perceptions. Ideophones for inner feelings and cognitive states emerge last as these are the most abstract and least directly grounded in sensorimotor experience (see discussion in Dingemanse 2012: 663-664).

The current study focuses on the Japonic language family [japo1237]. The ideophone lexicon of Standard Japanese (based on the Tokyo variety) [toky1238] is large and well described (e.g. Akita 2009; Hamano 1998; Iwasaki et al. 2017). Ideophones in Japanese are recognised as a distinct lexical class, with their own morphophonology and unique semantic properties (Akita 2012a, 2017). However, they do not form a coherent syntactic class. Instead, they are spread across multiple classes including the adverbial, verbal and nominal-adjectival classes, of which the adverbial and verbal are the most common. As discussed in Akita (2017: 20-24), Japanese ideophones fit the cross-linguistic prototype defined by Dingemanse (2019). They form a large, open lexical class; they are marked by their phonotactic exceptionality (e.g. Japanese ideophones are the only native words to occur with initial p- or initial voiced obstruents, among other peculiarities) and their use of a limited set of distinct morphological forms, including reduplicated (e.g. pikapika 'flashing') and short forms (e.g. pika? 'flash!'); and they depict sensory imagery, including sounds (e.g. pityon-pityon 'drip-drop'), movements (e.g. yoroyoro 'wobbly'), shapes (e.g. gizagiza 'jagged'), textures (e.g. nurunuru 'slimy'), bodily sensations (e.g. zukizuki 'throbbing') and even emotions (e.g. wakuwaku 'excited') (for a full overview of the depictive conventions used in Japanese ideophones see Hamano 1998). However, unlike other languages with large ideophone lexicons, there is a noticeable lack of dedicated ideophones for colours, tastes, and smells (Izumi 1976, as cited in Akita 2017: 21).

There are also some studies of ideophones in non-standard Japonic varieties (e.g. Kawagoe 2012; Takeda 2012; Tokunaga 2013), but these are generally less comprehensive and usually focus on a particular variety or semantic domain (e.g. emotion, pain, insect calls). The current study compares the relative development of the ideophone lexicon across multiple sensory domains and multiple linguistic varieties. Figure 2 shows the major varieties of the Japonic language family, along with their linguistic and geographical relations (Huisman et al. 2019). This study includes data from all varieties except Kyushu Japanese [kyus1238].

Linguistic variation across the Japonic language area as a whole has long been argued to exemplify the wave model of language change (Kawaguchi and Inoue 


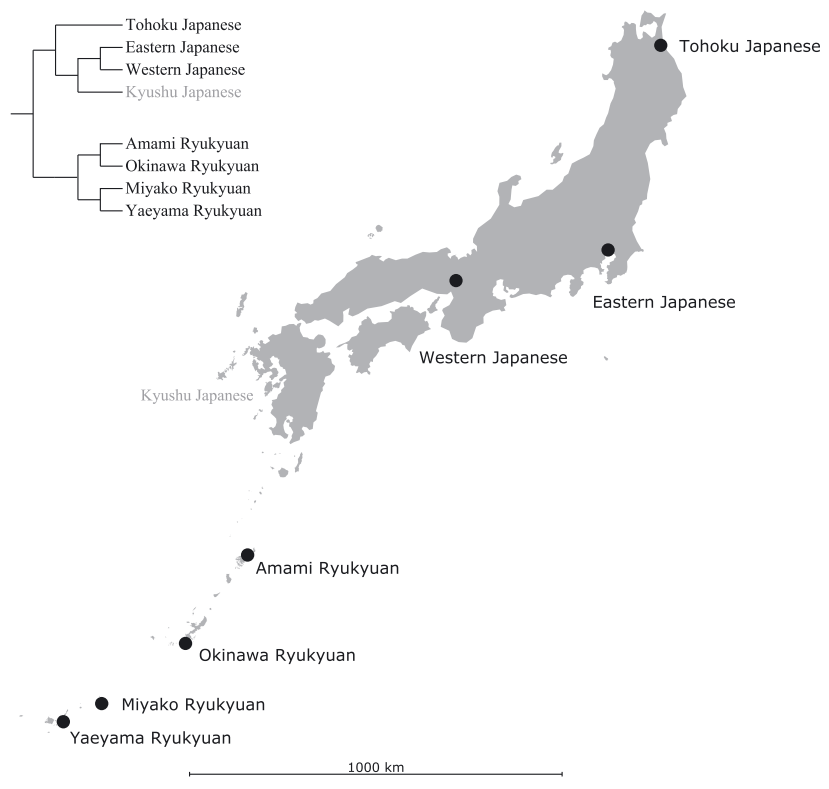

Figure 2: Major varieties of Japonic, including their linguistic and geographical relations. Varieties not examined in this study are greyed out.

2002; Onishi 2010; Yanagita 1930), in which new language forms originate in a cultural/political centre, then diffuse into peripheral areas. As the diffusion process takes time, older forms may still be used in peripheral areas even after they have been replaced in the centre. In the case of Japan, the historical cultural and political centre is the Kinai area around the former capitals Nara and Kyoto (where Western Japanese [west2607] is spoken), but this is gradually shifting to Tokyo (the modern capital, where Eastern Japanese [east2526] is spoken) in recent times (Kawaguchi and Inoue 2002). This places the Tohoku varieties [toho1244] and the Ryukyuan languages [ryuk1243] in the northern and extreme southern peripheries of the Japonic language area, and both areas have been shown to retain linguistic features that were found in Old Japanese but are no longer present in the standard language (see e.g., Kawaguchi and Inoue 2002). If this holds true for the ideophone lexicon as well, contrasting data from these varieties with data from the more central varieties of Eastern and Western Japanese can provide a means of understanding diachronic developments through synchronic variation.

The varieties examined in this study were selected for this reason. However, greater focus was given to the Ryukyuan varieties as these are the most endangered (Bairon et al. 2009), and their ideophone lexicons are the least well-described. 
They are also the varieties most removed from Standard Japanese, having split from the mainland varieties approximately 2000 years ago (Lee and Hasegawa 2011), being geographically isolated by a large body of water, and culturally and politically isolated as well, since they constituted their own kingdom for several centuries. This means that similarities between the ideophone lexicons of these varieties and the rest of Japonic are likely to reflect the older stages of the ideophone lexicon, while differences can be used to illuminate more recent individual developments.

Since there are no comprehensive dictionaries of ideophones in non-standard varieties, and corpora for these varieties (e.g. NINJAL 2001) are too small to provide a comprehensive overview, stimulus-based elicitation was used to provide a 'snapshot' of the ideophone lexicon in key areas (Dingemanse 2011a; Majid 2012; Tufvesson 2007). For ideophones, these key areas are centred around exteroceptive (related to our senses of sight, sound, touch, taste and smell) and interoceptive (related to our internal sense of the body and our emotions) perception.

Traditional methods in lexical typology, such as elicitation using word lists, can be problematic for cross-linguistic research on ideophones as many ideophones do not have simple translation equivalents. Rather than generalising the meaning of an ideophone, it is often easier to describe specific situations in which it is used (see discussion in Diffloth 1972). Stimulus-based elicitation is well-suited to this, as it allows typologists to start from the fully specified, concrete scenario and then elicit ideophones that can be used to describe it. Of course, not all sensory experiences translate equally well to stimulus-based elicitation, and it should not be considered an exhaustive technique (for more on this see discussion in Section 2.1). However, as a starting point to examine the ideophone inventory of a language, and particularly for comparative purposes (e.g. Berlin and Kay 1969; Levinson and Meira 2003; Majid et al. 2008), stimulus-based elicitation can be very useful.

In this case, the results of the stimulus-based elicitation task reveal a clear hierarchy of sensory meanings for ideophones in Japonic, which is consistent across the varieties examined and also largely consistent with the cross-linguistic hierarchy of ideophone meanings proposed by Dingemanse (2012). Speakers of peripheral varieties (Tohoku Japanese, Ryukyuan) used fewer ideophones than speakers of central varieties (Eastern Japanese, Western Japanese), and this difference was most pronounced in domains later in the implicational hierarchysupporting the hypothesis that these expanded most recently in central varieties.

However, other parts of the data contradict the implicational hierarchy, and so I suggest how the hierarchy might be revised to accommodate the Japonic languages and other languages of their type. These revisions are supported by consideration of cross-linguistic variation in the semantic structure of ideophone 
lexicons. Further independent evidence for the revised hierarchy is provided in an analysis of the polysemies of ideophones elicited during the study, where it was found that domains early in the hierarchy are the most likely sources in semantic extension, and later domains the most likely targets. Stimuli from earlier domains also elicited a wider variety of ideophone types, and a larger proportion of monosemous ideophones. These findings support the idea that it is easier to create ideophones or iconic representations in domains appearing early in the hierarchy compared to later domains. I conclude by considering directions for future research, including how the implicational hierarchy might be transformed into a 3-dimensional map of predicted paths of semantic extension, as a tool for crosslinguistic comparison (Haspelmath 2003).

\section{Methodology}

\subsection{Stimuli design}

A set of 56 sensory stimuli was developed to elicit descriptions of a range of sensory perceptions. This included 10 stimuli targeting auditory perception (representing sounds), 11 stimuli targeting visual perception (including six movement stimuli, three colour stimuli, and two shape stimuli), 15 stimuli targeting tactile perception (representing the tactile domains of rough-smooth, hard-soft and warm-cool), five stimuli targeting taste perception (representing the five basic tastes SWEET, SALTY, SOUR, BITTER and UMAMI), and five stimuli targeting smell perception (essential oils representing peppermint, lemongrass, floral, sweet orange and grapefruit smells). Interoceptive perceptions, such as the perception of pain, bodily sensations and emotions, were depicted using 10 manga (cartoon-style) images. The stimuli are shown in Figures 3 and 4. The audiovisual stimuli can also be downloaded from the online supplementary materials. Further details about the stimuli, including how they were selected and their individual effectiveness at eliciting ideophones, are provided in Section 1 of the online Appendix.

The stimulus kit was designed to compare the relative elaboration of the ideophone lexicon in key sensory domains across Japonic varieties, and also to investigate depictive conventions, the creation of novel ideophones, and the precision with which narrow perceptual contrasts are encoded by ideophones. As the stimulus kit was designed for field rather than lab settings, where participants' time is often limited and participants are not used to performing long tasks, the number of stimuli used to address these questions was fairly limited. Depictive conventions were investigated by including stimuli contrasting in intensity in the auditory and tactile domains, as well as stimuli contrasting in 


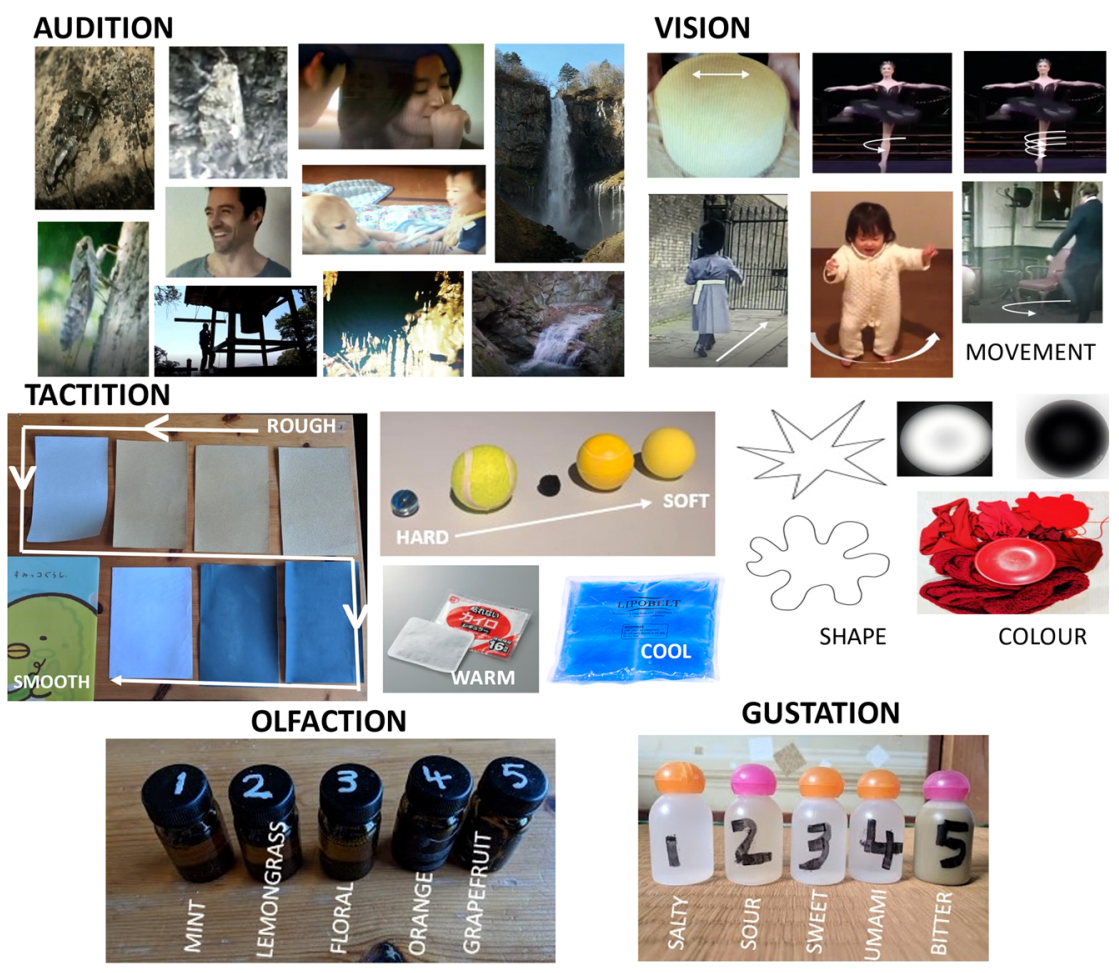

Figure 3: Stimuli used in the study to elicit descriptions of exteroceptive perceptions. Videos were sourced from YouTube.
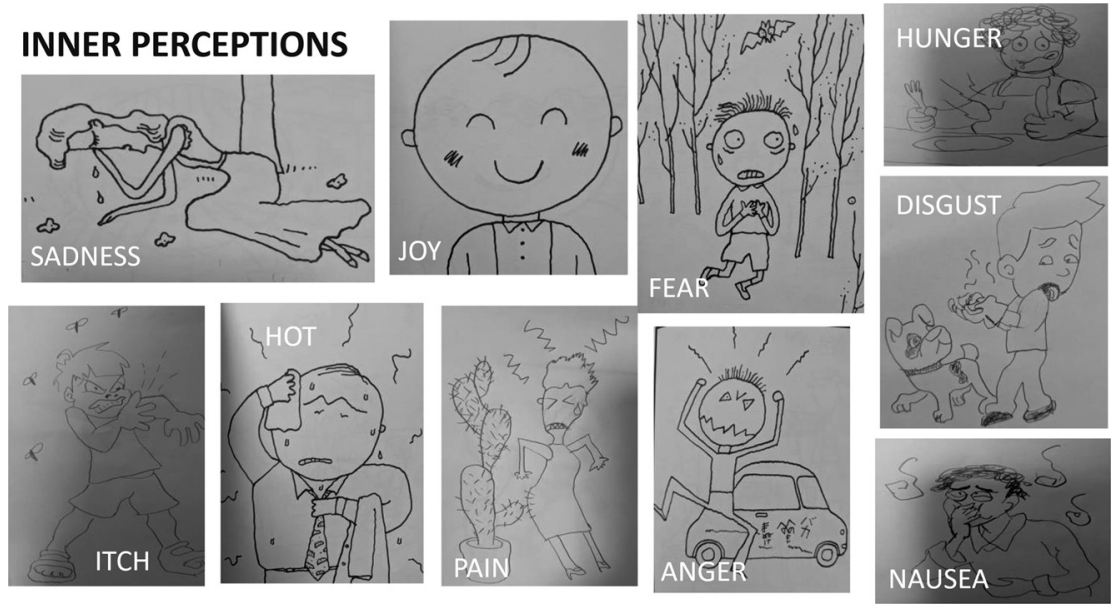

Figure 4: Stimuli used in the study to elicit descriptions of interoceptive perceptions. Manga drawings were taken from an illustrated dictionary of Japanese ideophones (Gomi 1989), or newly created for the study using the same drawing style. 
duration and temporal structure in the auditory and movement domains. The creation of novel ideophones was addressed through a clip from the Monty Python's Ministry of Silly Walks sketch (sourced from YouTube), since there was unlikely to be an existing ideophone to depict the strange manner of walking shown in the clip. The rough-smooth and hard-soft stimuli in the tactile domain were designed to investigate the precision with which fine perceptual contrasts are encoded, by including many stimuli varying subtly in roughness and hardness. Finally, the stimuli were designed to cover salient dimensions of key sensory domains, such as the five basic tastes, salient dimensions of tactile perception, basic classes of motion, etc. The dimensions of smell however are less well understood, and sourcing stimuli to represent them was also more difficult, so the smell stimuli were limited to scents that were available as essential oils. Further information about the design of the stimuli and a discussion of the results for these original research questions are provided in Section 1 of the online Appendix.

This study focuses on what the results of the task reveal about an implicational hierarchy of ideophone meanings. This was not one of the original research questions for which the stimulus kit was designed, and one limitation of using this stimulus kit to address this question is that the numbers of stimuli in each sensory domain are not consistent (e.g. there are many more tactile stimuli than shape stimuli), making comparisons across the sensory domains more difficult. This is addressed in the study by combining multiple methods. Thus, as well as the frequency of ideophone responses to stimuli from different sensory domains, the number of ideophone types that were elicited and the semantics of these ideophones are also considered. In these analyses, the differences between sensory domains become more clear. Statistical testing also found no significant correlation between the number of stimuli in a domain (sound, movement, shape, etc.) and the proportion of ideophone responses, $r=0.523, p=0.287$. However, for future research on this topic, stimulus sets with roughly equal numbers of stimuli from each domain would improve comparability between domains.

Since perception in the real world is multisensory (e.g. Calvert et al. 2004), and the meanings of real ideophones reflect this (e.g. Akita 2009: 14; see also Akita 2010; Morikawa 2002; Nuckolls 2019; Rhee and Koo 2017), wherever possible stimuli were designed to recreate these real-world, multisensory perceptual experiences. Hence, the sound stimuli were presented as videos, so that participants could see what was making the sounds as well as hear them; where there was audio in the videos of people moving (e.g. footstep sounds), this audio was not removed; and when presented with tactile stimuli, participants were able to see the stimulus as well as feel it, and hear any sounds it made when touched. However, the elicitation questions used with each stimulus targeted the particular sense 
modality under study (e.g. for sound stimuli, participants were instructed to comment on the sound; see Section 2.2).

Designing realistic stimuli was easier in some sensory modalities than it was in others. For example, due to the practicalities of creating, recreating and transporting taste and smell stimuli for the task, the taste and smell stimuli used in the study were presented as decontextualised, pure tastes and smells; a poor substitute for the multidimensional experience of taste and smell we have in real life (although previous studies have successfully elicited ideophones using similar stimuli, see e.g. Dingemanse 2011a; O’Meara et al. 2019). Similarly, while for the exteroceptive senses we can ask participants to listen to/watch/touch/taste/smell something, it is much more difficult to ask participants to feel something when eliciting ideophones for interoceptive sensations. In recognition of these limitations, the description of the Japonic ideophone lexicon presented in this study is not based solely on the results of the elicitation task but is also informed by information from follow-up questioning with participants about their use (or nonuse) of ideophones in particular domains, as well as (wherever possible) consultation of dictionaries and corpora.

\subsection{Task format}

The task was conducted as an oral interview, and audio recorded for the researcher's notes. The stimuli were presented to participants one by one, and participants were asked to describe the sound, movement, colour, shape etc. The order in which the different stimulus groups (i.e. sound stimuli, visual stimuli, smell stimuli etc.) were presented was randomly varied between participants, to negate any effects from the order of presentation. However, within each stimulus group the order of stimuli was kept constant.

Participants were told that the purpose of the research was to investigate sensory language in dialects, and were instructed to use their own dialect when describing the stimuli. However, all participants were bilingual in Standard Japanese, and the instructions in the task (Table 1) were given in Standard Japanese by a non-native speaker. Participants were not told prior to participating in the task that the research was particularly concerned with ideophones. This was so that they would not be encouraged to use more ideophones when describing the stimuli than they would naturally. However, to get a better understanding of the lexical availability of ideophones in different sensory domains, after the task (and when time permitted) the researcher asked participants about their use (or non-use) of ideophones in different sensory domains-particularly where no ideophones were elicited. 


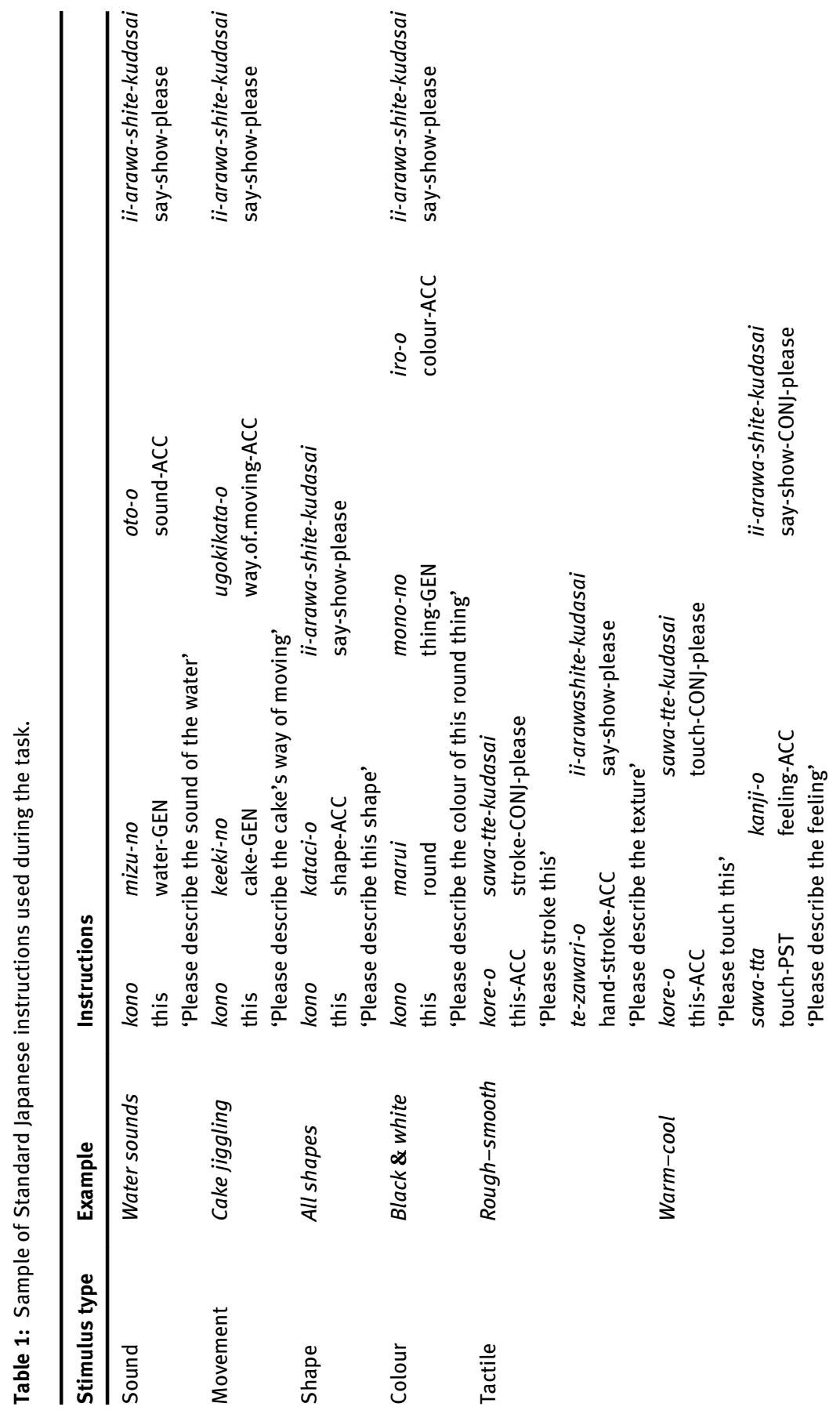




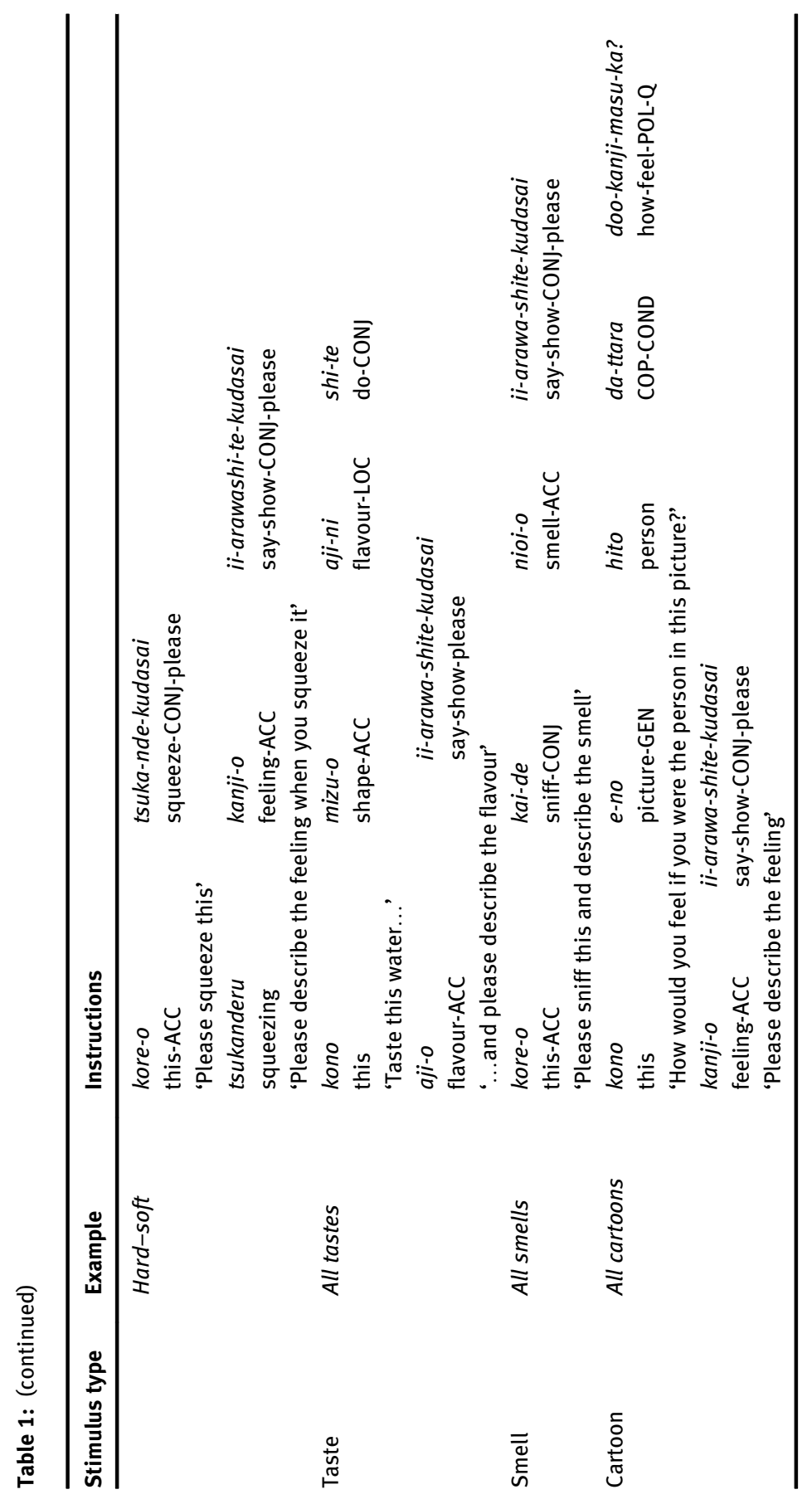


The instructions used in the task are shown in Table 1. The Standard Japanese verb iiarawasu, a compound of iu 'say' and arawasu 'show' was used as the main instruction verb for each stimulus because of its implicit reference to depiction (showing), the mode of representation of ideophones (Dingemanse 2012). The auditory and movement stimuli were presented to participants as videos, and participants were asked to describe the sound or movement. For the colour and shape stimuli, they were presented with the still image and asked to describe the colour/shape. For the tactile stimuli, they were given the object to touch and asked to describe the tactile feeling. For the smell stimuli, they were instructed to sniff the essential oils (with the labels removed so the name of the oil was not known) and describe the smell. Taste stimuli were presented as flavourings (salt, sugar, lemon juice, powdered bitter melon, and MSG) dissolved in water ( $15 \mathrm{ml} / 1 \mathrm{Tbsp}$ of flavouring dissolved in $40 \mathrm{ml}$ of water). Participants were asked to taste a little of the water and describe the taste. They were also given plain water to drink between tastings to remove any lingering tastes from a preceding stimulus. For the interoceptive stimuli, participants were asked to imagine that they were the person in the cartoon and describe their feelings.

A pilot study was conducted with a young female Standard Japanese speaker in Tokyo. In the pilot study, all stimuli representing sounds elicited ideophones, most stimuli representing movements and shapes elicited ideophones, most stimuli representing tactile sensations elicited ideophones, some stimuli representing inner perceptions elicited ideophones, and none of the stimuli representing colours, smells or tastes elicited ideophones. As these results were a good reflection of what is already known about the semantic distribution of ideophones in Standard Japanese (Akita 2017: 21), the study proceeded with this stimulus set for the other locations as well.

Ethics approval to conduct the task described in this section with the participants described in Section 2.3 was obtained from the Human Research Ethics Committee of the Australian National University (Protocol 2018/131).

\subsection{Locations and participants}

Data was collected from participants in and around the major locations of Tokyo and Kyoto in the centre of the country, Hachinohe city (Aomori prefecture, Tōhoku) in the north, and Amami-Ōshima island, Miyako island and Ishigaki island in the south. Using the package 'party' (Hothorn et al. 2006) on R version 3.5.1 (R Core Team 2018), classification trees were created to investigate differences between the use of ideophones/non-ideophones in response to the different stimuli by participants in each location (see Section 2.1 of the Appendix for the full output of these 
analyses). In these analyses, no significant difference was found between the responses from participants in Miyako and Ishigaki, and so these were collapsed under the label of Southern Ryukyuan for analyses. The same was true for participants in Kyoto and Tokyo, which were collapsed under the label of Standard Japanese. ${ }^{1}$

Table 2 shows the distribution of participants across the different locations, and how the data from these participants was classified for analyses. In Tokyo and Kyoto, it was possible to collect data from both younger and older speakers, but in the other locations most of the data came from older participants, as the younger generations rarely speak the local variety.

A total of 79 people participated in the study. However, not all participants were able to complete the entire task. This was particularly the case in the southern islands, where participants were often older and tired more easily. The Ns for each sub-component of the task are given with the presentation of the results in Section 3.

Table 2: Locations and participants.

\begin{tabular}{|c|c|c|c|}
\hline Location & Participants & Linguistic variety & $\begin{array}{l}\text { Classification for } \\
\text { analyses }\end{array}$ \\
\hline Hachinohe & $\begin{array}{l}12 \text { participants (seven females, mean } \\
\text { age } 55 \text {, range } 23-73 \text { ) }\end{array}$ & $\begin{array}{l}\text { Tohoku Japanese } \\
\text { [toho1244] }\end{array}$ & Tohoku Japanese \\
\hline Tokyo & $\begin{array}{l}\text { nine participants (nine females, mean } \\
\text { age } 41 \text {, range } 21-62 \text { ) }\end{array}$ & $\begin{array}{l}\text { Eastern Japanese } \\
\text { [east2526] }\end{array}$ & Standard Japanese \\
\hline Kyoto & $\begin{array}{l}11 \text { participants ( } 10 \text { females, mean age } \\
43 \text {, range } 24-77 \text { ) }\end{array}$ & $\begin{array}{l}\text { Western Japanese } \\
\text { [west2607] }\end{array}$ & \\
\hline $\begin{array}{l}\text { Amami- } \\
\text { Ōshima }\end{array}$ & $\begin{array}{l}15 \text { participants (seven females, mean } \\
\text { age } 66 \text {, range } 45-85 \text { ) }\end{array}$ & $\begin{array}{l}\text { Amami Ryukyuan } \\
\text { [amam1245] }\end{array}$ & Northern Ryukyuan \\
\hline Miyako & $\begin{array}{l}20 \text { participants ( } 13 \text { females, mean age } \\
68, \text { range } 52-102 \text {, with one participant } \\
\text { of } 21 \text { ) }\end{array}$ & $\begin{array}{l}\text { Miyako Ryukyuan } \\
\text { [miya1259] }\end{array}$ & $\begin{array}{l}\text { Southern } \\
\text { Ryukyuan }\end{array}$ \\
\hline Ishigaki & $\begin{array}{l}12 \text { participants (six females, mean age } \\
80 \text {, range } 56-95 \text { ) }\end{array}$ & $\begin{array}{l}\text { Yaeyama Ryukyuan } \\
\text { [yaey1239] }\end{array}$ & \\
\hline
\end{tabular}

1 There was one exception to this, which was that participants from Kyoto used more ideophones than participants from Tokyo in response to the smell stimuli $(\mathrm{p}<0.001)$. However, this was a difference between Kyoto participants and participants from all other regions of Japan, rather than a difference between Tokyo and Kyoto participants in particular. For this reason, I have kept the label of 'Standard Japanese' to refer to the Eastern and Western varieties in contrast to Tohoku Japanese and the Ryukyuan varieties. 


\subsection{Response coding}

Responses were coded as either (a) containing an ideophone, (b) not containing any ideophone, or (c) non-responses. Non-responses were used when a participant did not know how to describe a stimulus. For ideophone responses, the specific ideophone used was also recorded. Multiple responses were allowed per participant, and all were noted and included in counts. However, multiple responses were rare (representing only $5 \%$ of total responses), and the correlation between the distribution of ideophone/non-ideophone responses for different stimulus types when multiple responses were included versus excluded was near-identical $(\mathrm{r}=0.9991)$.

Secondly, for ideophone responses which had related meanings in other sensory domains, these other sensory domains were also coded. For example, the ideophone gasagasa was elicited in response to the rough tactile stimuli, but in addition to its tactile meaning it can also refer to the sound of rough objects rubbing together. Thus, this ideophone elicited in the tactile domain was coded as having a related meaning in the domain of sound. For standard forms, coding was based on definitions in Yamaguchi (2003). For non-standard forms, coding was based on consultation with the participant who produced the ideophone and, where possible, with other community members as well. This involved asking them whether the ideophone could also be used to describe something of the other stimulus types (i.e. sound, movement, shape, tactile, inner perception, etc.), and whether those additional meanings were related to its original usage in the elicitation task. A list of non-standard ideophones elicited during the task, along with their (multi)sensory meanings, is provided in Section 6.

\section{Results}

\subsection{Frequency of ideophones in response to different stimulus types}

Leaving aside the non-responses for the moment, this section considers the effect of stimulus type on the frequency of ideophone versus non-ideophone responses for Standard Japanese, Tohoku Japanese, Northern Ryukyuan and Southern Ryukyuan. For Standard Japanese, the sound stimuli always elicited ideophones, after which the frequency of ideophone responses decreased gradually from sound to movement, tactile, shape, inner perceptions, and then smell stimuli. Colour and taste stimuli rarely elicited ideophones compared to stimuli of other types. The 
distribution of ideophone responses in non-standard varieties follows the same basic pattern, except that non-standard speakers generally used less ideophones across all stimulus types. This is shown in Figure 5.

To statistically test the differences between the frequency of ideophone responses by stimulus type, using the package 'ImerTest' (Kuznetsova et al. 2017) binomial regression models with ideophone response (yes/no) as the dependent variable, stimulus type as the independent variable, and stimulus and participant as random effects were constructed, with a separate model for each linguistic variety. Figure 6 summarises the results of these models, the full output of which is provided in Section 2.2 of the Appendix. In the figure, black shaded cells indicate a significantly greater frequency of ideophones elicited for one stimulus type (in the rows) over another (in the columns). Grey shaded cells indicate that this difference was not statistically significant. In some cases, the relevant comparison could not be made due to there being either no ideophones or no non-ideophones elicited for stimuli of that type. This is indicated using striped patterned cells. Thus, for the Japanese varieties the comparison between sound stimuli and stimuli of other types was not possible as no non-ideophones were elicited in response to sound stimuli. Similarly, for the Ryukyuan varieties the comparison to colour and taste was not possible as no ideophones were elicited in response to these stimuli.

Figure 6 shows that where comparisons were possible, sound stimuli elicited ideophones significantly more frequently than stimuli of all other types. For Standard Japanese, movement stimuli elicited ideophones significantly more frequently than stimuli of all other types except sound. However, for all other varieties, the difference between the frequency of ideophones elicited in response to movement, tactile, and shape stimuli was not statistically significant. For Standard Japanese, the difference between the frequency of ideophones elicited in response to tactile and shape stimuli was also not statistically significant. Tactile

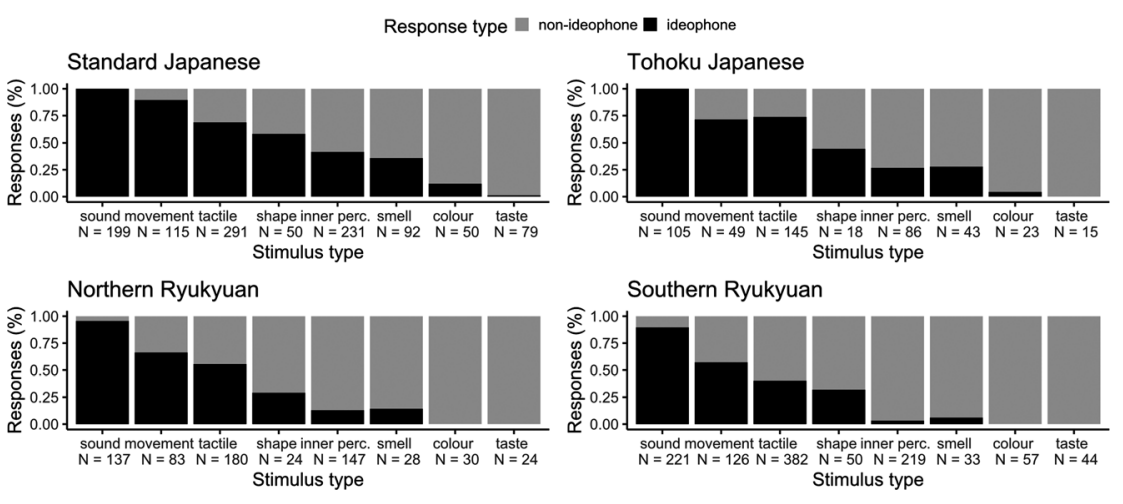

Figure 5: Responses to stimuli of different types, for Standard Japanese, Tohoku Japanese, Northern Ryukyuan and Southern Ryukyuan. 

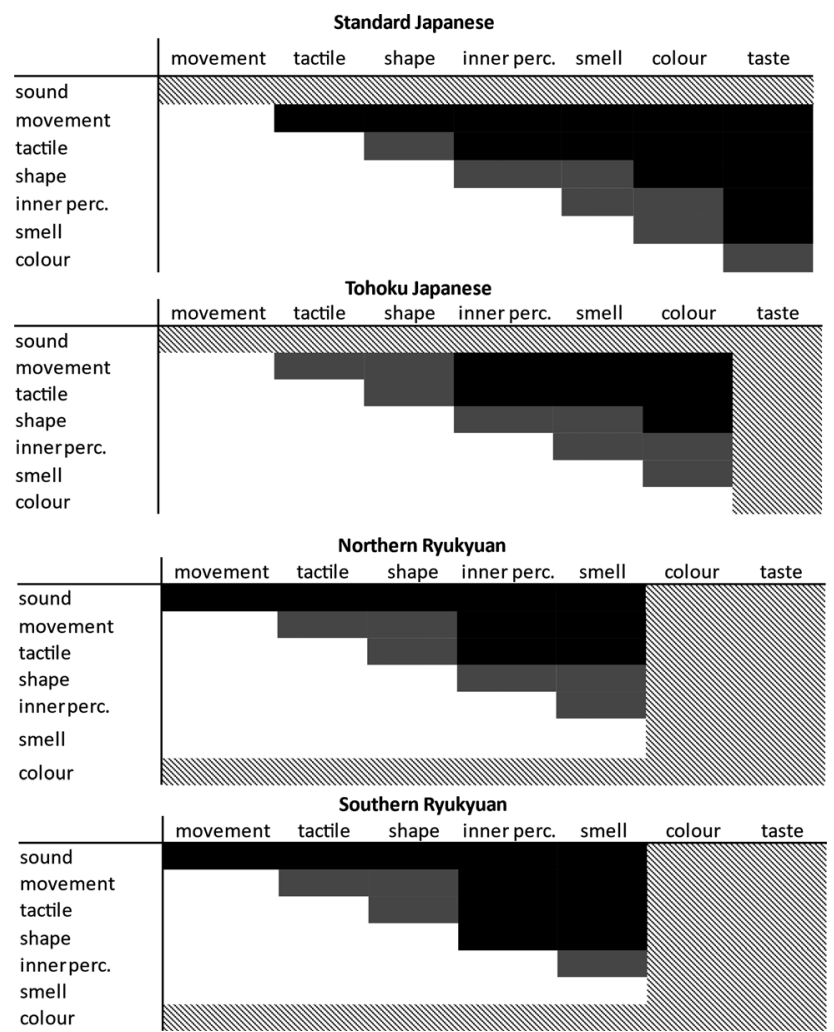

Figure 6: Comparative frequency of ideophones elicited for different stimulus types across the four linguistic varieties. Black shaded cells indicate a significantly greater frequency of ideophones elicited for one stimulus type (in the rows) compared to another stimulus type (in the columns). Grey shaded cells indicate that this difference was not statistically significant. Striped patterned cells indicate that the relevant comparison was not possible due to either zero cases of ideophones or zero cases of non-ideophones.

stimuli elicited ideophones significantly more frequently than stimuli for inner perceptions, smell, colour and taste for all varieties, but shape stimuli elicited ideophones significantly more frequently than stimuli of these other categories only in Southern Ryukyuan. This is likely an artefact of the design of the stimulus set; as the number of shape stimuli was very small (only 2) responses from a much greater number of participants were needed before any comparisons reached statistical significance, and the largest amount of data was collected in Southern Ryukyuan. The frequency of ideophones in response to inner perception, smell and colour stimuli did not differ significantly for any variety. However, for Standard Japanese stimuli for inner perceptions and smells elicited ideophones significantly 
more frequently than taste stimuli. This comparison was not possible for the other varieties as no taste ideophones were elicited for these varieties.

Next, a series of chi-squared tests were conducted to compare the differences between varieties in terms of their ideophone usage for different stimulus types. In these tests, ideophone usage was compared across the varieties for each stimulus type separately. The results are shown in Table 3, which lists the chi-square value ( $\mathrm{df}=3$ for all tests), $\mathrm{p}$ value, Cramer's $\mathrm{V}$, and standardised residuals for ideophone responses in each linguistic variety for each stimulus type. The $\mathrm{p}$-values given have been corrected for multiple comparisons using a Benjamini-Hochberg procedure (Benjamini and Hochberg 1995). The standardised residuals reflect the strength of the difference between observed and expected values, in which values higher than two or lower than -2 represent significantly more or fewer ideophone responses than expected, respectively. In this analysis, high standardised residuals indicate that there were more ideophone responses for that domain in that variety when compared to the other varieties, and vice-versa for low standardised residuals. To highlight these differences, the standardised residuals in Table 3 are colour-coded along a gradient from red (strong negative association) to green (strong positive association).

Table 3: Results of chi-squared tests comparing the association between ideophone use and linguistic variety, for different stimulus types.

\begin{tabular}{|c|c|c|c|c|c|c|c|c|}
\hline & \multicolumn{8}{|c|}{ stimulus type } \\
\hline & sound & movement & tactile & shape & $\begin{array}{l}\text { inner } \\
\text { perc. }\end{array}$ & smell & colour & taste \\
\hline$X^{2}(3)$ & 33.09 & 31.94 & 75.99 & 8.96 & 107.3 & 13.55 & 10.93 & 1.05 \\
\hline$p$ & $<.001$ & $<.001$ & $<.001$ & .034 & $<.001$ & .006 & .016 & .787 \\
\hline \multirow[t]{2}{*}{ Cramer's V } & .224 & .293 & .276 & .251 & .396 & .263 & .261 & .081 \\
\hline & \multicolumn{8}{|c|}{ standardised residuals } \\
\hline $\begin{array}{l}\text { Standard } \\
\text { Japanese }\end{array}$ & 3.61 & 5.27 & 5.11 & 2.8 & 9.29 & 2.96 & 3.18 & 1.03 \\
\hline $\begin{array}{l}\text { Tohoku } \\
\text { Japanese }\end{array}$ & 2.39 & 0.06 & 4.61 & 0.2 & 1.34 & 0.32 & -0.01 & -0.32 \\
\hline $\begin{array}{l}\text { Northern } \\
\text { Ryukyuan }\end{array}$ & 0 & -1.09 & -0.19 & -1.42 & -2.78 & -1.53 & -1.3 & -0.42 \\
\hline $\begin{array}{l}\text { Southern } \\
\text { Ryukyuan }\end{array}$ & -5.36 & -4.23 & -7.97 & -1.82 & -7.92 & -2.87 & -2.01 & -0.61 \\
\hline
\end{tabular}


Table 3 shows that Standard Japanese speakers used significantly more ideophones than speakers of other varieties for all stimulus types except taste, for which only one ideophone response was elicited in the entire data set (from a Standard Japanese speaker). Tohoku Japanese speakers used the next most ideophones after Standard Japanese speakers, followed by Northern Ryukyuan speakers, and then Southern Ryukyuan speakers, who used the least ideophones. The standardised residuals indicate that these differences between the varieties were greatest in the responses to inner perception stimuli, followed by tactile stimuli.

\subsubsection{Ideophone types}

The analyses in Section 3.1 deal with ideophone tokens, but it is also useful to consider the data in terms of the number of ideophone types elicited for different stimuli. This is shown in Figure 7, where the numbers of types have been normalised by the total number of responses collected for those stimuli. Since the overall distribution of ideophone responses by stimulus type did not differ significantly between the varieties, the data for all varieties was collapsed for this analysis. As seen in Figure 7, the distribution of ideophone types mirrors the distribution of ideophone tokens, with one exception; although tactile stimuli elicited ideophones more frequently than shape stimuli (Section 3.1), shape stimuli elicited relatively more ideophone types.

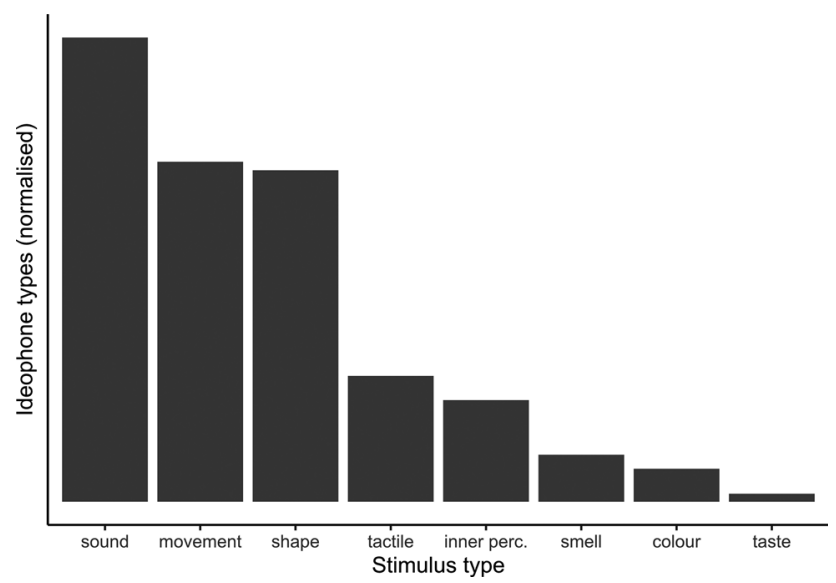

Figure 7: Ideophone types elicited for different stimuli, normalised by response numbers. 


\subsection{Semantic analysis of ideophones}

Next, the semantics of elicited ideophones were analysed. This revealed further differences between the sensory domains with regards to (a) their likelihood of eliciting monosemous versus polysemous ideophones, and (b) their likelihood of functioning as a source versus target in semantic extension. This information is summarised in the network diagram in Figure 8, created using the package 'igraph' (Csardi and Nepusz 2006). The nodes in the diagram represent different sensory domains, with the $\mathrm{N}$-values indicating the number of ideophone tokens elicited by stimuli in that domain. The size of the node represents the proportion of these ideophones which were monosemous. Polysemous ideophones are represented by arrows going into the node, from domains in which the ideophone had a related meaning. Thus, for example, ideophones elicited in response to stimuli from the domain of inner perceptions had related meanings in the domains of sound, movement and shape. The ideophone dokidoki is an illustration, as it was elicited in response to a stimulus depicting fear, but also evokes the sound of a heartbeat associated with that emotion. This is indicated by an arrow going from sound to inner perceptions. The width of the arrow represents the proportion of ideophones elicited in the target domain (in this case, inner perception) which had this related association in the source domain (sound). Thus, we can see that many ideophones in the domain of inner perceptions had related associations in the domains of sound and movement, but fewer had related associations in the shape domain.

In a few rare cases, the meaning of an ideophone was not tied to any sensory domain(s) in particular, but was better expressed by some suprasensory property, applicable to perceptions in all modalities. ${ }^{2}$ To indicate this, an italicised 'suprasensory properties' node was added to the network, although it lacks an $\mathrm{N}$ as, unlike the other domains, suprasensory properties was not a category of stimulus used in the task. The most common suprasensory ideophone elicited during the task was honnori, which describes any kind of low-intensity perception. It was used to describe both the white and black colour stimuli (in terms of the colour being faded); the sweet taste stimulus (in terms of the taste being weak); and the floral smell (in terms of the smell being faint).

First, Figure 8 shows that the greatest proportion of monosemous ideophones were elicited in response to sound stimuli, then movement stimuli, shape, and finally tactile stimuli. No monosemous ideophones were elicited in response to stimuli from other domains. This information is also displayed as a bar graph in Figure 9, which highlights that the proportion of monosemous

2 See Marks (1978). Intensity, duration, and quality are the three most generally agreed upon suprasensory properties. 

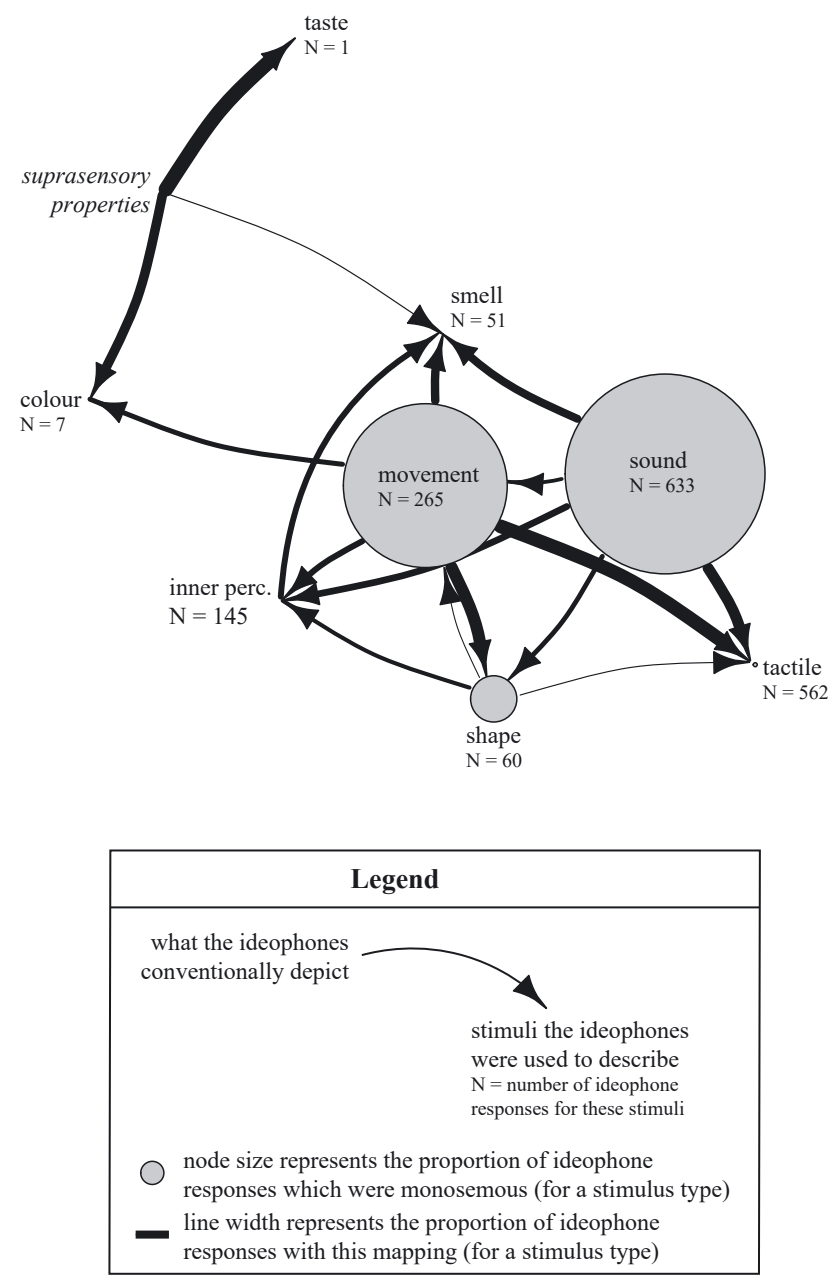

Figure 8: Network diagram showing semantic extensions in ideophones elicited during the task.

ideophones decreases dramatically after movement. Second, domains with more monosemous ideophones were more likely to act as sources in semantic extension, while other domains were more likely to be targets of such extensions. For example, Figure 8 shows that while sound and movement acted as sources for semantic extension to five other sensory domains, and shape to three, the other domains in the diagram were more often targets than sources of semantic extension. Third, the location of the nodes in the diagram reflects their integration into the semantic network of Japanese ideophones, revealing colour and taste to be the least connected domains. That these domains were predominantly 


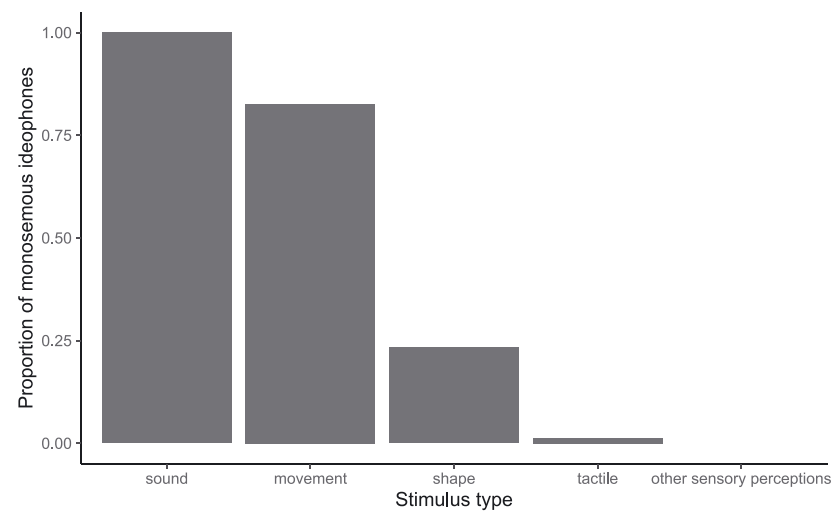

Figure 9: Proportion of elicited ideophones which were monosemous, by stimulus type.

described in terms of suprasensory properties rather than being linked to other sensory domains supports this.

\subsection{Analysis of non-responses}

Finally, as a measure of the effectiveness and appropriateness of the stimuli for different participants, a separate analysis was conducted to explore the effect of stimulus type and linguistic variety on the likelihood of eliciting a non-response. Figure 10 shows the proportion of non-responses versus responses for each stimulus type and for each variety. As seen in the figure, the number of non-responses overall was very low (representing only $2 \%$ of total trials). Non-responses to
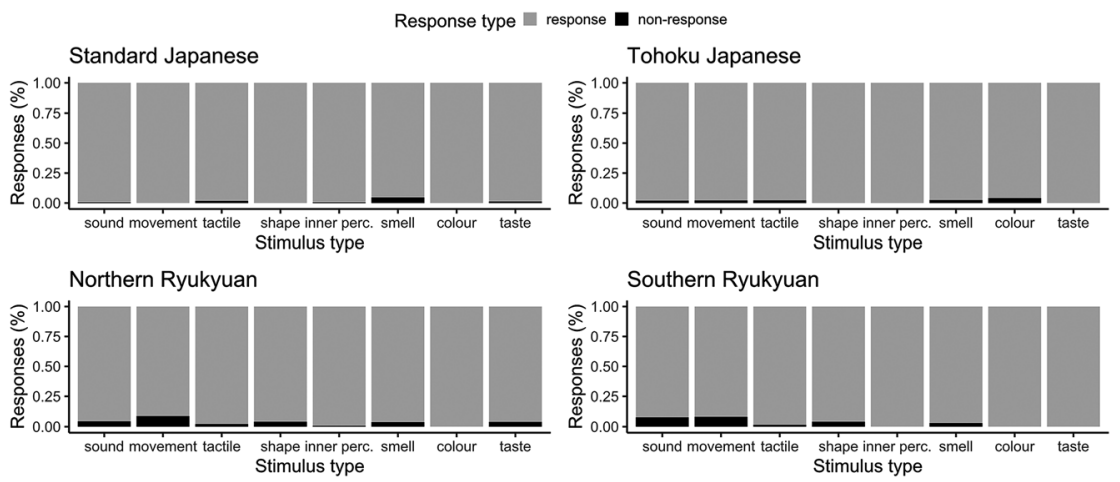

Figure 10: Distribution of non-responses for stimuli of different types, for Standard Japanese, Tohoku Japanese, Northern Ryukyuan and Southern Ryukyuan 
smell and tactile stimuli were found across all varieties, but there were more non-responses to sound and movement stimuli in the non-standard varieties, particularly Ryukyuan. The Ryukyuan varieties also had a higher proportion of non-responses to the shape stimuli.

To test these differences, a binomial regression model was constructed with response/non-response as the dependent variable; stimulus type, linguistic variety, and the interaction between stimulus type and linguistic variety as fixed effects; and stimulus and participant as random effects. The model found a significant effect of linguistic variety on the likelihood of eliciting a non-response, in that non-responses were more common from Ryukyuan speakers $(p<0.05)$. There was also a negative interaction between linguistic variety and stimulus type, such that the difference between Southern Ryukyuan and Standard Japanese was smaller for tactile stimuli $(\mathrm{p}<0.05)$. The full output of this model is provided in Section 2.3 of the Appendix.

\section{Discussion}

\subsection{Differences between stimulus types}

The results in Section 3 highlight that there is a clear hierarchy of the senses for Japanese ideophones, with some sensory domains being easier to depict using ideophones than others. First, as we saw in Section 3.1, some sensory domains are more likely to be described using ideophones than others. Second, as we saw in Section 3.1.1, some sensory domains are described using a wider variety of ideophones than others. Third, as we saw in Section 3.2, some sensory domains contain more monosemous ideophones, and act as sources for semantic extension, while others contain more polysemous ideophones, and are targets of such extensions.

Combining these results, the hierarchy of the senses which emerges for Japanese ideophones is sound < movement < shape < tactition < inner perceptions $<$ smell $<$ colour $<$ taste. Not every division is clear in each individual analysis, but the hierarchy as a whole emerges when multiple analyses are combined. For instance, movement stimuli only elicited ideophones significantly more frequently than shape and tactile stimuli in the Standard Japanese data, ${ }^{3}$ and they did not elicit more ideophone types than shape stimuli (Sections 3.1 and 3.1.1). However,

3 As discussed in Section 1 of the online Appendix, the movement stimuli were partly designed to be difficult to describe, and only Standard Japanese participants tended to create novel ideophones to describe them, perhaps because they were more likely to have been familiar with abstract naming tasks (for more on this see discussion in Section 4.8). 
semantic analysis revealed that the movement domain contained a much greater proportion of monosemous ideophones, and was a more important source in semantic extension, including to the shape and tactile domains (Section 3.2). On this basis, movement appears before shape and tactition in the hierarchy. Similarly, no significant difference was found between the frequency of ideophone responses to shape and tactile stimuli, but shape stimuli elicited comparatively more ideophone types and more monosemous ideophones, as well as being a more important source in semantic extension-including to the tactile domain. For these reasons, shape is ordered before tactition in the hierarchy.

Stimuli for inner perceptions and smells also elicited ideophones in roughly equal proportions, but stimuli for inner perceptions elicited a greater variety of ideophone types, and the domain of inner perceptions was actually a source for semantic extension to the smell domain. Also, although no monosemous Japanese ideophones for inner perception were elicited in this study, these can be found in dictionaries (examples include zukizuki 'throbbing pain' and tsuun 'stinging feeling in the nose', Yamaguchi 2003), whereas there is no record of a Japanese ideophone specifically for smell, nor colour, nor taste (Izumi 1976, as cited in Akita 2017: 21), despite the existence of many large, dedicated dictionaries of Japanese ideophones (e.g. Asano 1978; Kakehi et al. 1996; Yamaguchi 2003). Moreover, ideophones that were elicited in response to smell, colour, and taste stimuli did not actually describe smells, colours, or tastes. Smells were described using ideophones referring to the movement of the smell (sometimes also with the associated sound) rather than to the smell itself, e.g. funwari 'swelling' or suQ 'whooshing'. Or, they described the smell's effect on the body/mind of the participant, as with tsuun, which depicts a tingling in the nose, or sukkiri, which refers to feeling refreshed. Colour stimuli also elicited ideophones depicting movement rather than colour, e.g. kowaan, which depicts something opening up, for the white stimulus, and doyoon, which depicts something clouding over, for the black stimulus. This is different to the use of ideophones with additional associations of movement or sound to refer to tactile perceptions, or to emotions, as these usages include reference to a particular tactile perception (e.g. rough, smooth), or a particular emotion (e.g. happy, sad), whereas the ideophones used with smell, colour, and taste stimuli did not refer to individual smells, colours, or tastes in particular. For this reason, following other researchers (e.g. Akita 2017; Izumi 1976) I do not consider Japanese to possess dedicated smell, colour, or taste ideophones, despite the use of ideophones in these domains. This is further reflected in participants' use of ideophones depicting suprasensory properties, rather than modality-specific forms, in these domains-although Figure 8 shows that the domain of smell is slightly more integrated into the ideophone lexicon than colour or taste. 


\subsection{Differences between Japonic varieties}

Further support for the hierarchy comes from the comparison between the four Japonic varieties. If there was no hierarchy of ideophone meanings, we would not expect the distribution of ideophones across the stimulus types to be so consistent across all varieties. Moreover, the differences between the Standard Japanese responses and the responses from non-standard varieties-i.e. that speakers of non-standard varieties used ideophones less often-were most pronounced in domains appearing later in the hierarchy (inner perceptions and texture) ${ }^{4}$ and in linguistic varieties at the furthest edges of the Japonic linguistic area, supporting the idea that the Standard Japanese ideophone lexicon expanded into these domains most recently.

Further independent evidence for the late emergence of ideophones for inner perception in Standard Japanese comes from analysis of historical texts. Modern Standard Japanese usages of ideophones to refer to inner perceptions are not attested in texts from earlier time periods, but appear only in later ones (Nakazato 2002, 2004a). As a comparable example from the tactile domain, one Southern Ryukyuan speaker in this study used the ideophone nurunuru to describe a video of a cake wobbling. This usage would be considered strange in Standard Japanese, where nurunuru is solely used to refer to a slimy tactile sensation. However, in the Nara era (710-794 CE) nurunuru was recorded as referring to a loose movement (e.g. of hair or vines) (Yamaguchi 2003: 362). In line with the wave model of linguistic diffusion in Japan (Onishi 2010; Kawaguchi and Inoue 2002; Yanagita 1930), it is likely that the Southern Ryukyuan data reflects this older usage, with the tactile meaning of nurunuru being a more recent development in Standard Japanese, which may not yet have spread to varieties at the furthest periphery of the Japonic linguistic area.

An alternative analysis is that the lesser usage of ideophones by speakers of non-standard varieties represents a general effect of language loss in these varieties (Bairon et al. 2009). However, this would not explain why these differences are particularly prominent in later domains in the hierarchy (Section 3.1). Differences in the usage of ideophones by speakers of non-standard varieties also suggest a real, qualitative difference between the ideophone lexicons of these varieties and the standard variety. Specifically, ideophones were used with a broader range of meanings in non-standard varieties. For example, speakers of non-standard

\footnotetext{
4 Smell, colour, and taste also appear late in the hierarchy, but the difference between varieties was not as marked in these domains as ideophones in these domains are not a prominent feature of any variety.
} 
varieties used a wider variety of ideophones to describe the rough tactile stimuli, including forms that have very restricted usages in modern Standard Japanese (e.g. to specifically depict rough skin or hair). That speakers of non-standard varieties, but not the standard variety, used these forms interchangeably for the general meaning of 'rough' suggests that their meanings in the non-standard varieties are broader. A similar example can be found in the domain of movement, where Ryukyuan speakers described both jiggling and swaying movements with forms that would only be used for swaying movements in Standard Japanese (e.g. yuruyuru, yoroyoro). Polysemous and synonymous ideophones have been shown to undergo semantic narrowing over time in Standard Japanese (Nakazato 2002, 2004a, 2004b), and the data in this study suggests that these processes of semantic narrowing are not yet widespread at the periphery of the Japonic linguistic area. This supports an analysis of the data in terms of linguistic variation rather than simply language loss.

\subsection{The Japonic data in the cross-linguistic context}

The hierarchy of sensory domains for Japanese ideophones presented here shares some key similarities to the cross-linguistic implicational hierarchy for the semantic development of ideophone lexicons proposed by Dingemanse (2012): SOUND < MOVEMENT < VISUAL PATTERNS < OTHER SENSORY PERCEPTIONS < INNER FEELINGS AND COGNITIVE STATES. The first two semantic domains in Dingemanse's hierarchy-SOUND and MOVEMENT-are also the first two semantic domains in the Japanese hierarchy, while INNER FEELINGS AND COGNITIVE STATES (here shortened to 'inner perceptions') appears relatively late in both hierarchies. However, there are also some key differences, and so I suggest how the implicational hierarchy could be revised to better accommodate that data from Japanese and other languages like it.

Firstly, the third semantic domain to appear in Dingemanse's hierarchy is VISUAL PATTERNS, which was said to involve things like 'spatial configuration' and 'surface appearance' (Dingemanse 2012: 663). While spatial configuration is easy to describe using Japanese ideophones, as reflected by the prevalence of shape ideophones in this study, aspects of surface appearance-specifically colour-were much more difficult to describe using ideophones. This has also been reported for ideophones in Hindi [hind1269] (Diatka 2014) and Pastaza Quechua [past1249] (Nuckolls 2019). Therefore, I suggest renaming the third category in the implicational hierarchy to explicitly exclude reference to colour. Drawing on the literature on perception, the term FORM is suggested as form perception is considered separate to 
both movement perception (which comes earlier in the hierarchy) and colour perception (which comes later) (Livingstone and Hubel 1988). The term FORM could then be used in its broadest sense to refer to the wide range of visual phenomena outside of movement and colour that are described by ideophones in various languages, such as big, small, tall, short, long, thin, fat, narrow, tight, thick, steep, straight, kinky, wavy, curved, curled, round, rectangular, humped, heaped, wide, spacious, empty, spiky, crooked, arched, bulging, drooping, stooping, bent over, baggy, loose, frayed, dishevelled, puckered, sticking out, buck-toothed, holey, etc. (examples taken from Watson et al. 2001: 395).

The fourth category in Dingemanse's hierarchy is OTHER SENSORY PERCEPTIONS, which, by process of elimination, would include tactile, taste, and smell perceptions. However, the results in Section 3 demonstrate that while tactile ideophones form a robust category in Japanese, describing tastes and smells using Japanese ideophones is more difficult. Along with colour, smell and taste are the only domains that lack dedicated (monosemous) ideophones, and they were also the only domains to elicit ideophones depicting suprasensory properties, rather than modality-specific forms. Even inner perceptions were easier to describe using Japanese ideophones than smells or tastes, as demonstrated by the wider variety of ideophone types elicited for inner perceptions (Section 3.1.1), and by the use of ideophones depicting inner perceptions to describe smells, but not vice-versa (Section 3.2). Although not attested in the data from this study, ideophones for inner perceptions and tactile sensations are also used to describe taste in Japanese, in the absence of dedicated taste ideophones (Fukushima et al. 2017; Hayakawa et al.2000). These findings highlight that tactition and even interoception are more central to the Japanese ideophone system than taste and smell, which is problematic for the original implicational hierarchy.

Again, this situation is not unique to Japanese, but is also reported in Pastaza Quechua, which has ideophones that refer to haptic perceptions and emotional states, but not to taste and smell (Nuckolls 2019). The Khoisan language G|ui [gwii1239] also appears to possess “TOUCH” ideophones, while lacking ideophones for taste and smell (Nakagawa 2011, 2013). To my knowledge, Dingemanse (2011a) is the only study that systematically compares the relative elaboration of the ideophone lexicon across sensory domains for a language (Siwu [siwu1238]) possessing tactile, smell, and taste ideophones. Also using stimulus-based elicitation, Dingemanse found that roughly three quarters of the unique responses to tactile stimuli were ideophones, compared to less than half of the unique response to taste stimuli, and only a tiny fraction of the unique responses to smell stimuli (2011a: 81).

These findings suggest a more privileged position for tactition in the hierarchy when compared to taste and smell, and so I suggest introducing TEXTURE as a 
separate category preceding OTHER SENSORY PERCEPTIONS in the hierarchy. I refer to texture perception rather than to tactition generally as not all tactile dimensions are equally commonly represented by ideophones. For example, the warm-cool stimuli in this study elicited ideophones in only $7.6 \%$ of cases, compared to $43 \%$ of cases for the hard-soft stimuli, and $77 \%$ of cases for the roughsmooth stimuli. Analysis of Siwu data (Dingemanse and Majid 2012) also reveals a greater diversity of forms for hard-soft and rough-smooth perceptions compared to warm-cool perceptions, and a cluster analysis showed that ideophones for hardsoft and rough-smooth form a coherent supercategory (HAPTIC TOUCH) to which warm-cool ideophones do not belong. Texture can be defined as referring to the fine structural details of surfaces, thus including tactile dimensions like roughsmooth, hard-soft and sticky-slippery, while excluding dimensions like warm-cool (Hsiao and Bensmaia 2008). It makes sense to refer to TEXTURE rather than to tactition generally as the next step in the hierarchy, because our perception of texture involves the integration of information from our senses of vision and audition (Klatzky and Lederman 2010)-also domains where, as we've seen, ideophones are very common (Dingemanse 2012; Van Hoey and Lu in prep.; this study). On the other hand, temperature perception is more closely connected to our senses of pain and itch-domains where ideophones are comparatively rare (Van Hoey and Lu in prep.).

Finally, the final category in the original hierarchy, INNER FEELINGS AND COGNITIVE STATES, is also inconsistent with the Japanese hierarchy-where ideophones for inner perceptions actually appear before ideophones for colour, smell, and taste. However, here it is not so straightforward to revise the hierarchy to accommodate Japanese, since other languages display the opposite pattern. For example, descriptions of ideophones in some African languages either make no reference to ideophones for inner feelings and cognitive states despite mentioning ideophones for colours, smells and tastes (e.g. Fortune 1962 on ideophones in Shona [shon1251]), or explicitly comment that these are underdeveloped when compared to the more concrete exteroceptive senses, e.g. Childs's (2001: 70) question, "Why are Japanese ideophones psychological in their orientation and African ideophones so perceptual or sensual?” (see also Akita 2013: 335; Dingemanse 2012: 663). To address this, I suggest that we remove the category of INNER FEELINGS AND COGNITIVES STATES from the end of the hierarchy, and instead subsume ideophones for inner feelings and cognitive states into the more general category of OTHER SENSORY PERCEPTIONS, which could include all sensory domains that for some languages prove difficult to describe using ideophones (e.g. colour, taste, smell, and inner perceptions). This results in the revised hierarchy, SOUND $<$ MOVEMENT < FORM < TEXTURE < OTHER SENSORY PERCEPTIONS. 


\subsection{Testing the revised hierarchy}

The purpose of the original hierarchy was to describe the semantic development of ideophone lexicons, meaning that languages possessing ideophones in one category in the hierarchy should also possess ideophones in all categories preceding this category in the hierarchy. In this section, I show that this also holds true for the revised hierarchy proposed here, using Dingemanse's original sample of languages, to which I have added another 18 languages from diverse phyla. This is shown in Table 4. Languages from Dingemanse's original sample are shown in bold, while languages not included in that original sample and with ideophone lexicons that contradict the original hierarchy (including Japanese) are shown in italics. Grey shading indicates the presence of ideophones in a particular category of the hierarchy, while a lack of shading indicates that no ideophones in this category are recorded for the language. For the category of OTHER SENSORY PERCEPTIONS, the specific perceptions the ideophone lexicon is reported to cover are elaborated, with 'interoception' used as a cover term for the original hierarchy's INNER FEELINGS AND COGNITIVE STATES.

As seen in the table, the prediction that languages possessing ideophones in one category of the hierarchy will also possess them in all preceding categories holds for this extended sample, but the final column of the table shows that after the development of ideophones for texture languages vary in the distribution of ideophones across sensory domains. Languages with ideophones that only reference sound are comparatively rare, but Syuba [kaga1252] (Tibeto-Burman) and Warekena [guar1293] (Arawakan) are proposed as two examples. Languages with ideophones that reference both sound and movement are much more common, and show a wide geographical distribution. Languages with ideophones depicting static visual forms on top of sound and movement are harder to find, although this may simply be because within languages sound and movement ideophones are more common than ideophones depicting form. However, examples I have found are Jaminjung [jami1236], a Yirram (non-Pama-Nyungan) language from Australia, and Komnzo [komn1238] (a Yam language from Papua New Guinea). Many languages possess ideophones in a broad array of sensory domains beyond SOUND, MOVEMENT and FORM, but of these TEXTURE is the only domain where ideophones were consistently found across all the languages examined. I also found one language, G|ui [gwii1239] (Khoe), where ideophones have been found for SOUND, MOVEMENT, FORM, and TEXTURE, but no other sensory domains, which lends further support for the placement of TEXTURE as an intermediary rung between FORM and OTHER SENSORY PERCEPTIONS in the hierarchy. 


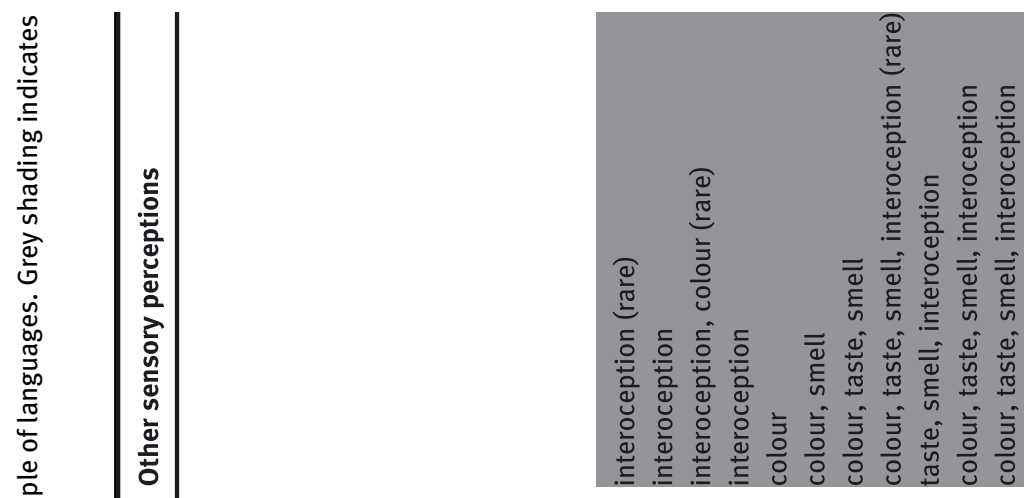

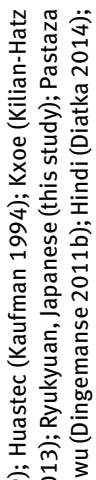

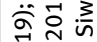

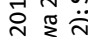

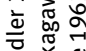
尊离

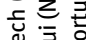

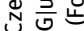

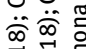
定容

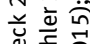
象 눙

苕

产

ñ 六

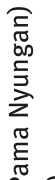

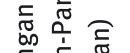

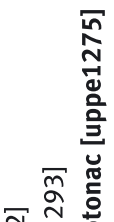

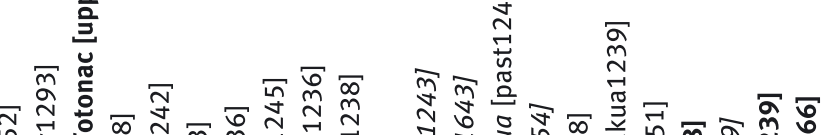

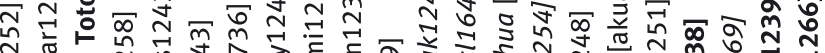

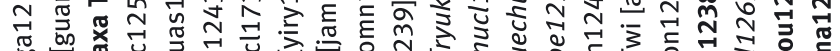
o

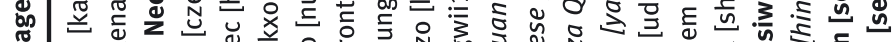

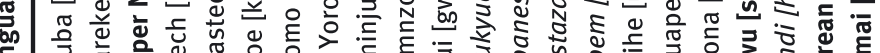

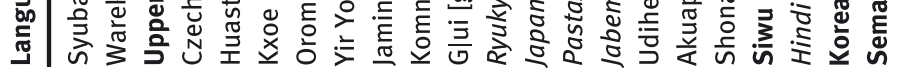




\subsection{Theoretical justification}

Only languages for which a conscientious effort has been made to describe the ideophone lexicon including its relevant sensory domains were included in Table 4. However, it should be noted that the descriptive record is never perfect, and just as this study found counterexamples to the original hierarchy, so future work may find counterexamples to the revised hierarchy. That said, because they are motivated, we might hypothesise that form-meaning mappings in iconic lexicons will be constrained by the limitations of the communicative medium, and the hierarchy of meanings we find for ideophones is indeed the one we would predict from this hypothesis.

This explains why SOUND forms the base of the hierarchy, even though vision is more salient cross-linguistically (San Roque et al. 2015; Viberg 1983). In the original hierarchy, it was suggested that MOVEMENT follows SOUND because of the causal-temporal relation between them (Dingemanse 2012: 663), and because the articulatory and structural properties of speech also lend themselves to the depiction of MOVEMENT. The latter point applies equally well to the depiction of FORM, which would explain why FORM follows MOVEMENT in the hierarchy. For example, the articulatory properties of vowels in Japanese ideophones are used to iconically represent form, with lip rounding for protruding shapes, spread lips for flat shapes, and the relative size of the oral cavity being mapped to the relative size of the referent (Hamano 1998: 172-173; see also Egbokhare 2001: 95 for a similar analysis of Emai [emai1242] shape ideophones). At the level of word structure, the presence or absence of vowel alternations can reflect alternations (or an absence of alternation) in form, e.g. gizagiza 'zig-zag' and gunyagunya 'curvy', versus piin 'long and pointed'.

It is less obvious why TEXTURE should follow FORM in the hierarchy, since there is no clear way in which the physical properties of speech are inherently better suited to the depiction of TEXTURE than to any of the other categories following FORM in the hierarchy. However, our perception of texture is tightly bound to our perception of SOUND, MOVEMENT and FORM (see Klatzky and Lederman 2010 for a review), and this connection to these earlier domains could explain why ideophones for TEXTURE appear next. As an example, studies have found an overlap in the neurons that fire in response to both auditory and somatosensory input (Fu et al. 2003; Schroeder et al. 2001). This means that when gasagasa, a Japanese ideophone depicting the sound of dry objects rubbing together, is also used to refer to a dry tactile sensation the tight link between our senses of audition and tactition may make this usage feel more iconic. This was 
suggested as an explanation for tactile words in English receiving relatively high iconicity ratings (Winter et al. 2017). It is also similar to the original motivation for the position of MOVEMENT in the hierarchy, and indeed just as we find languages whose movement ideophones are entirely onomatopoeic, so we find languages whose texture ideophones are entirely onomatopoeic also (G|ui, from Table 4, is an example) (Nakagawa 2011).

The other perceptual domains where we find ideophones-colour, taste, smell, and interoception-are not as directly connected to the lower end of the implicational hierarchy, which would explain why the distribution of ideophones in these domains is more varied cross-linguistically; none of these are clearly easier or more natural to depict in speech. For this reason, the lexical availability of ideophones in these domains may be more influenced by language-specific factors, such as the cultural salience of a perceptual domain (e.g. Majid et al. 2018), rather than language-independent features of our speech architecture and perceptual processing systems-although this is not to say that these cannot also play a role. As an example, given the close connection between taste and smell (which also share overlapping perceptual architecture), we might hypothesise that if a language has ideophones in one of these domains, it will also have them in the other. Korean seems to be a good example, as Korean smell ideophones are reported to be primarily an extension of their taste ideophones (Rhee and Koo 2017). Huehuetla Tepehua [hueh1236] (Totonacan) ideophones are also reported to sometimes combine taste and smell reference (O'Meara et al. 2019). Understanding relations between sensory modalities and how these may influence their iconic representation in ideophones is an important area for future research, and exploring these relationships will require more complex tools than a simple, linear hierarchy (as indeed Dingemanse 2012 foreshadowed). I discuss how semantic maps may provide one means of doing this in the next section.

\subsection{Future directions: Semantic maps}

Semantic maps are an established tool for comparing patterns of semantic extension across languages (Haspelmath 2003), and although they are usually used for grammatical markers, they could also be a useful tool for typological research into ideophones (as suggested by Dingemanse 2012: 664; see also Akita and McLean to appear; Van Hoey and Lu in prep.), particularly if their pathways of semantic extension are to a certain extent predictable (as suggested in this study). 
As an illustration, Figure 11 is a 3-dimensional map of semantic extensions found in the Japanese data from this study. Arrows are used to indicate the most common directions of semantic extension.

To the best of my knowledge, there is only one comparable study of semantic extensions for ideophones in another language, Pastaza Quechua. In Pastaza Quechua, tactile ideophones are reported to form a subcategory of movement ideophones, while ideophones for inner perceptions form a subcategory of sound ideophones (Nuckolls 2019). This means that the map in Figure 11 works for ideophones in both Pastaza Quechua and Japanese. However, not all of the pathways found in the Japanese data are also attested in Pastaza Quechua. This is shown in Figure 12, which uses the map in Figure 11 as a base to compare trajectories of semantic extension for ideophones in the two languages, based on the data in this study and in Nuckolls (2019). Lines that are greyed out indicate pathways of semantic extension not attested in the data from that language. For pathways that are attested, the width of the line is used to indicate the frequency of such extensions. For legibility, a three-way contrast between very common pathways (represented by a thick line), fairly common pathways (represented by a regular line), and rare pathways (represented by a thin line) is probably the largest number of contrasts that can be clearly represented.

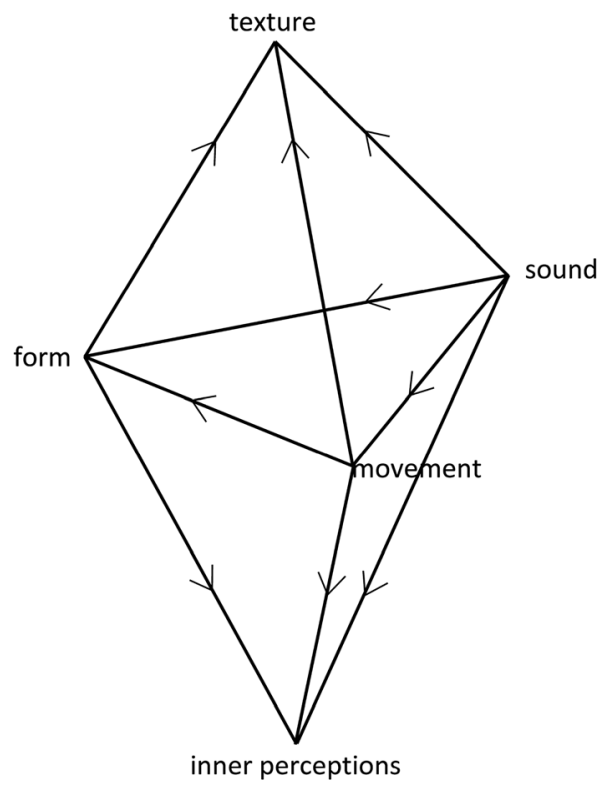

Figure 11: 3-dimensional map of semantic extensions for Japanese ideophones. 

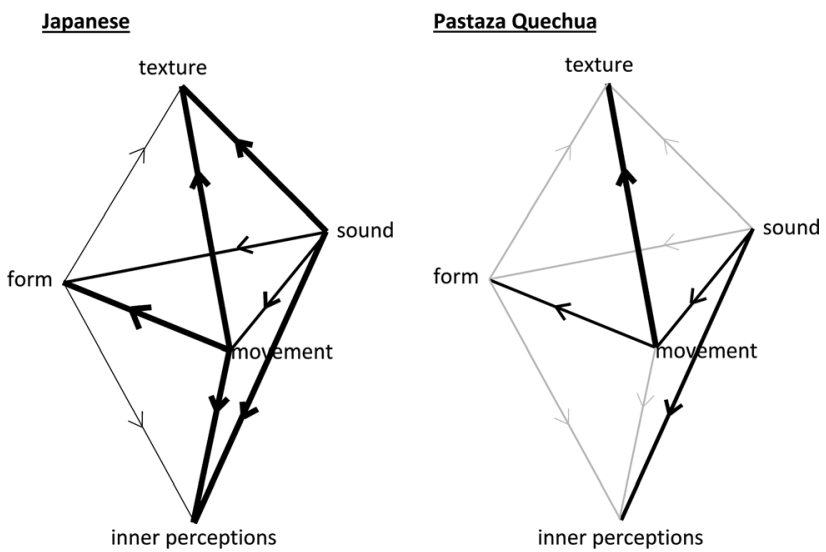

Figure 12: Comparison of semantic extensions in Japanese and Pastaza Quechua ideophones, using the map in Figure 11 as a base. Greyed out lines indicate pathways not attested, while the width of black lines corresponds to the frequency of the extension.

From Figure 12 we can see that a wider variety of pathways for semantic extension are found in Japanese ideophones, e.g. in Japanese both movement and sound are sources for semantic extension to the domains of texture and inner perceptions, whereas in Pastaza Quechua only movement ideophones have extended reference to texture, and only sound ideophones have extended reference to inner perceptions. As Nuckolls explains, in the Pastaza Quechua cultural context sounds are imbued with emotional significance, and so when onomatopoeia are used these rarely encode "mere sound" but are instead "one tool for expressing animistic thought by allowing nonhuman life to use sounds that express the emotions" (Nuckolls 2019: 184). The semantic maps in Figure 12 highlight this difference between the role of sound in the ideophone lexicons of Japanese and Pastaza Quechua.

In this way, semantic maps could be a useful tool for comparative research on semantic extensions in ideophone lexicons, to establish whether there is any pattern to which pathways are more or less common across languages and, if there is, to think about how such patterns might be explained. With more researchers now tackling the difficult task of documenting ideophone meanings (e.g. De Schryver 2009; Ibarretxe-Antuñano 2019; Nuckolls et al. 2017; Nuckolls 2019; Osada et al. 2019; Rhee and Koo 2017), this is a promising avenue for future research. However, there are likely to be some challenges along the way, which I discuss in the next section. 


\subsection{Future challenges: Data comparability}

The first challenge for comparative research on ideophone lexicons is identifying the ideophones themselves, and distinguishing them from related phenomena. Although well-established as a lexical class, depending on the language, ideophones do not always constitute a distinct grammatical category and this can pose challenges for identifying them. Japanese is one example, and in non-specialist dictionaries Japanese ideophones are rarely distinguished from other adverbs. Not all researchers distinguish them from ordinary reduplicatives either. However, for a semantic typology that emerges from the constraints of depiction, these distinctions are very important.

As an illustration, this study has demonstrated that colour is a domain difficult to represent in Japanese ideophones, but Japanese does have reduplicated colour terms, akaaka 'bright red' being one example. Akaaka resembles Japanese ideophones in many ways-it is marked, it shares the same morphosyntactic properties as many ideophones, and it has a vivid, sensory meaning. However, it is not a depictive sign, as evidenced by the fact that small alterations in its form do not correspond to small alterations in its meaning (e.g. akaaka 'bright red', okaoka 'hilly', c.f. patapata 'heavy raindrops', potapota 'light raindrops'). ${ }^{5}$ It also does not exhibit the same depictive conventions as Japanese ideophones, for which total reduplication signifies repetition, not intensity (which is signified by partial reduplication; Hamano 1998). Distinguishing ideophones from related phenomena is not always simple, but requires an in-depth knowledge of the ideophone lexicon as a whole and how it functions as a cohesive system with its own depictive conventions. This is a challenge that must be addressed by lexicographers, particularly for the purposes of semantic typology, since, as this example demonstrates, the semantic typology of words which are not depictions-even if they resemble ideophones in other ways-will not be constrained in the same ways as the semantic typology of true ideophones, which is driven by their depictive nature.

Another issue that remains to be addressed is the question of how to classify ideophone meanings. Currently, there is no generally agreed upon system, and researchers vary in how they ascribe ideophones to semantic domains. For example, an ideophone depicting a numbing of the mouth when eating spicy food may be categorised as a pain ideophone in one study, a tactile ideophone in another, or a taste ideophone in a third. Obviously, this is problematic for semantic typology, and developing a unified system for the semantic categorisation of

5 For more on depiction see e.g. Goodman (1968), Dingemanse (2011b, 2019); also relevant is Diffloth's (1972) discussion of lexical discreteness. 
ideophone meanings should be a focus for future research (see also Van Hoey and $\mathrm{Lu}$, in prep.).

Finally, as mentioned in Section 4.5, the implicational hierarchy proposed here is based on the descriptive record of ideophone lexicons-a record which will always be incomplete, posing a challenge for semantic typology. Stimulus-based elicitation as used in this study is one way to address this (Majid 2012), and should be a focus for future research. The case of Huehuetla Tepehua [hueh1236] (Totonacan) is a good example. Although the language has been the subject of in-depth documentation for several years, it was not until stimulus-based elicitation was used to elicit smell descriptions that a wealth of smell ideophones were discovered (O’Meara et al. 2019). This highlights the value of stimulus-based elicitation for documentary research on ideophone lexicons, and incorporating stimulus-based elicitation into such research is one way to improve the reliability of the descriptive record for future scholars. In the interests of this, the final section of this paper discusses the effectiveness of the stimuli used in this study, including areas of improvement for future research.

\subsection{Effectiveness of stimuli (analysis of non-responses)}

The effectiveness of the stimuli used in the task and their appropriateness for different participants is reflected in the analysis of the non-responses in Section 3.3. The higher proportion of non-responses to smell and tactile stimuli was found across all varieties. In the case of smell, this is likely not a fault of the stimuli but a consequence of smells being difficult to describe in general (Majid et al. 2018). In the case of the tactile stimuli, these were specifically designed to elicit very narrow perceptual contrasts, which may not always be encoded, and so the higher proportion of non-responses here can be seen as a consequence of stimuli design (see Section 1 of the Appendix for more details).

A significantly higher proportion of non-responses was found in non-standard varieties, particularly Ryukyuan, and particularly in the domains of sound, movement, and shape. For sound stimuli, this difference was primarily attributable to one stimulus (08-tsukutsuku.mp4 in the online supplementary materials), a cicada which is common around Tokyo and Kyoto, but more rarely found in the northern part of Japan where Tohoku Japanese is spoken, and practically never found in the Ryukyus. This made the cicada call difficult to describe for some Tohoku Japanese and Ryukyuan speakers, although that the call was so unfamiliar also resulted in some interesting novel forms, e.g. tukutukutee, tyikutyikuhoo and zyizyizyizyibii, some of which resemble the standard Japanese form for the call (tsukutsukuboosyi). 
As a general rule when conducting stimulus-based elicitation, unfamiliar stimuli should be avoided as these are more likely to elicit non-responses. However, in the case of ideophones it may be interesting to include a few unfamiliar stimuli as well, to examine how participants tackle the challenge of describing them. This is possible for ideophones because of the flexibility of ideophone lexicons, which allow for the spontaneous creation of novel ideophones for specific situations (Dingemanse 2014). The higher proportion of non-responses to the movement stimuli was also driven by one particular video (02-Sillywalk.mp4 in the online supplementary materials) that was very difficult to describe. Only the Standard Japanese speakers tended to attempt to describe it, again often using interesting novel forms, e.g. ho?o?o?, or n:gyu? (see discussion in Section 1.2 of the Appendix for more details).

Decisions about whether to include unfamiliar or challenging stimuli in a task should be made with the intended audience for the task in mind. As mentioned, the Standard Japanese speakers handled unfamiliar stimuli more easily than Ryukyuan participants, who were generally a lot older and had less experience with formal education, which is likely to have made this abstract naming task more difficult for them. This was particularly true for the shape stimuli, which were the most abstract and elicited a particularly high proportion of non-responses from Ryukyuan participants. The shape stimuli also tended to elicit more source-based descriptions (e.g. 'it looks like a starfish', or 'it looks like an amoeba') rather than ideophones or other adjectives from all participants. Since the meanings of ideophones are usually tied to specific contexts (e.g. Akita 2012b), it makes sense that abstract stimuli would elicit ideophones more rarely. It is therefore my recommendation for future studies to use as concrete stimuli as possible, such as images of real objects or, even better, the actual three-dimensional objects themselves when eliciting ideophones. As mentioned in Section 3.3, the higher proportion of non-responses in Southern Ryukyuan was not found in the tactile domain, and I believe this is attributable to the effectiveness of using real, concrete stimuli in this domain.

\section{Conclusion}

This study has re-examined an implicational hierarchy for the semantic development of ideophone lexicons from the perspective of comparative data from Japonic. The Japonic data is shown to generally support the idea of a hierarchy of meanings for ideophones, with some small modifications to the semantic categories involved. A revised version of the hierarchy, SOUND < MOVEMENT $<$ FORM $<$ TEXTURE $<$ OTHER SENSORY PERCEPTIONS is proposed, which is supported by cross-linguistic variation in the semantic structure of ideophones lexicons, including variation within Japonic. The revised hierarchy also describes 
patterns of semantic extension in Japanese ideophones, providing further independent evidence for the hierarchy as well as directions for future research, which could transform the implicational hierarchy into a three-dimensional map of trajectories for semantic extension.

\section{List of non-standard ideophones}

Table 5: List of non-standard ideophones elicited during the task, including their sensory domains, meanings, associated stimuli, and associated linguistic varieties.

\begin{tabular}{|c|c|c|c|c|}
\hline $\begin{array}{l}\text { Ideophone } \\
\text { (IPA) }\end{array}$ & $\begin{array}{l}\text { Sensory } \\
\text { domains }\end{array}$ & Meaning & Associated stimuli & $\begin{array}{l}\text { Associated } \\
\text { linguistic } \\
\text { variety }\end{array}$ \\
\hline afafa & Sound & $\begin{array}{l}\text { cicada call } \\
\text { (general) }\end{array}$ & 08-tsukutsuku.mp4 & Amami $^{6}$ \\
\hline birubiru & $\begin{array}{l}\text { Sound, move- } \\
\text { ment, texture }\end{array}$ & smooth & smooth plastic (tactile) & Amami \\
\hline dzokkidzokki & Movement & stiff & $\begin{array}{l}\text { 01-Marching.mp4, } \\
\text { 02-Sillywalk.mp4 }\end{array}$ & Tohoku \\
\hline ga:siga:sí & Sound & $\begin{array}{l}\text { cicada call } \\
\text { (general) }\end{array}$ & 08-tsukutsuku.mp4 & Miyako \\
\hline gi:sigi:si & Sound & $\begin{array}{l}\text { cicada call } \\
\text { (high-pitched, } \\
\text { general) }\end{array}$ & $\begin{array}{l}\text { 08-tsukutsuku.mp4, } \\
\text { 09-miimii.mp4 }\end{array}$ & Miyako \\
\hline gittagitta & Sound & $\begin{array}{l}\text { boisterous } \\
\text { laughter }\end{array}$ & 07-Manlaugh.mp4 & Miyako \\
\hline$g^{w} a: n$ & Sound & bell & 04-Bell.mp4 & $\begin{array}{l}\text { Miyako, } \\
\text { Tohoku }\end{array}$ \\
\hline $\begin{array}{l}\text { pafupafu, } \\
\text { afuafu, } \\
\text { afaafa }\end{array}$ & $\begin{array}{l}\text { Movement, } \\
\text { tactile }\end{array}$ & $\begin{array}{l}\text { puffing up, airy, } \\
\text { light }\end{array}$ & $\begin{array}{l}\text { soft foam ball (tactile), soft } \\
\text { felt ball (tactile) }\end{array}$ & Miyako \\
\hline$p^{h}$ itfagip ${ }^{h}$ itfagi & $\begin{array}{l}\text { Sound, } \\
\text { movement }\end{array}$ & $\begin{array}{l}\text { quickly, with a } \\
\text { swish }\end{array}$ & 01-Marching.mp4 & Amami \\
\hline $\begin{array}{l}\text { piripari } \\
\text { saisai }\end{array}$ & $\begin{array}{l}\text { Movement } \\
\text { Sound }\end{array}$ & $\begin{array}{l}\text { back and forth } \\
\text { cicada call } \\
\text { (general) }\end{array}$ & $\begin{array}{l}\text { 01-Marching.mp4 } \\
\text { 08-tsukutsuku.mp4 }\end{array}$ & $\begin{array}{l}\text { Amami } \\
\text { Miyako }\end{array}$ \\
\hline
\end{tabular}


Table 5: (continued)

\begin{tabular}{|c|c|c|c|c|}
\hline $\begin{array}{l}\text { Ideophone } \\
\text { (IPA) }\end{array}$ & $\begin{array}{l}\text { Sensory } \\
\text { domains }\end{array}$ & Meaning & Associated stimuli & $\begin{array}{l}\text { Associated } \\
\text { linguistic } \\
\text { variety }\end{array}$ \\
\hline fingufingu & Movement & sashaying & 03-Firststeps.mp4 & Miyako \\
\hline fo:fo: ga:ra & Sound & $\begin{array}{l}\text { cicada call } \\
\text { (general) }\end{array}$ & 08-tsukutsuku.mp4 & Miyako \\
\hline 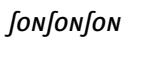 & Sound & $\begin{array}{l}\text { cicada call } \\
\text { (general) }\end{array}$ & 08-tsukutsuku.mp4 & Ishigaki \\
\hline takutaku & $\begin{array}{l}\text { Movement, } \\
\text { shape }\end{array}$ & $\begin{array}{l}\text { flowing/ } \\
\text { wobbling move- } \\
\text { ment, curvy } \\
\text { shape }\end{array}$ & $\begin{array}{l}\text { 04-Cheesecakejiggle.mp4, } \\
\text { 01-bouba.jpg }\end{array}$ & Miyako \\
\hline ting $^{j}$ ating ${ }^{j} a$ & Movement & stiff-legged & 02-Sillywalk.mp4 & Amami \\
\hline$t s \dot{t}$ & Sound & $\begin{array}{l}\text { cicada call } \\
\text { (high-pitched, } \\
\text { general) }\end{array}$ & 09-miimii.mp4 & Miyako \\
\hline tuntikanti & Shape & uneven & 01-bouba.jpg, 02-kiki.jpg & Ishigaki \\
\hline
\end{tabular}

\section{Online supplementary materials}

The appendix, data, stimuli, figures, and code for the analyses can be found online at https://osf.io/y9rk2/.

Acknowledgments: I would like to thank the anonymous participants in Hachinohe, Tokyo, Kyoto, Amami, Miyako, and Ishigaki, without whom this research would not be possible. I would also like to thank Catherine Travis, who supervised me to conduct the research; Kimi Akita, who provided helpful feedback on the design of the stimulus kit; and finally Mark Dingemanse and a second anonymous reviewer, who provided valuable feedback on the manuscript which has greatly improved it.

Funding: Fieldwork including data collection for this research was carried out with funding from the Australian Department of Foreign Affairs and Trade's New Colombo Plan program.

\section{References}

Aikhenvald, Alexandra Y. 1998. Warekena. In Geoffrey K. Pullum \& Desmond C. Derbyshire (eds.), Handbook of Amazonian languages, vol. 4, 225-439. Berlin and New York: Mouton de Gruyter. 
Akita, Kimi. 2009. A grammar of sound-symbolic words in Japanese: Theoretical approaches to iconic and lexical properties of mimetics. Kobe: Kobe University PhD Dissertation.

Akita, Kimi. 2010. An embodied semantic analysis of psychological mimetics in Japanese. Linguistics: An Interdisciplinary Journal of the Language Sciences 48(6). 1195-1220.

Akita, Kimi. 2012a. Phonosemantic evidence for the mimetic stratum in the Japanese lexicon. In Proceedings of the thirty-fourth annual meeting of the Berkeley Linguistics Society, 1-12. Berkeley, CA: Berkeley Linguistics Society.

Akita, Kimi. 2012b. Toward a frame-semantic definition of sound-symbolic words: A collocational analysis of Japanese mimetics. Cognitive Linguistics 23(1). 67-90.

Akita, Kimi. 2013. The lexical iconicity hierarchy and its grammatical correlates. In Lars Elleström, Olga Fischer \& Christina Ljungberg (eds.), Iconic investigations, vol. 12, 331-349. Amsterdam: John Benjamins Publishing Company.

Akita, Kimi. 2017. Grammatical and functional properties of mimetics in Japanese. In Noriko Iwasaki, Peter Sells \& Kimi Akita (eds.), The grammar of Japanese mimetics: Perspectives from structure, acquisition and translation, 20-34. London \& New York: Routledge.

Akita, Kimi \& Bonnie McLean. to appear. Onsyootyoo-tikaku-no niti/ei-taisyoo: Imi-tizu-ni yoru kentoo [A contrastive study of Japanese and English speakers' sound-symbolic perception: A semantic-map approach]. In Kazuko Shinohara \& Ryoko Uno (eds.), Zikken-ninti-gengogaku [Experimental cognitive linguistics]. Tokyo: Hitsuji Shobo.

Alpher, Barry. 1994. Yir-Yoront Ideophones. In Leanne Hinton, Johanna Nichols \& John J. Ohala (eds.), Sound symbolism, 161-177. Cambridge: Cambridge University Press.

Aoyama, Hideo. 1991. Tyoosengo syootyoogo ziten [A dictionary of Korean sound-symbolic words]. Tokyo: Daigaku Shorin.

Asano, Tsuruko (ed.). 1978. Giongo/gitaigo ziten [A dictionary of mimetics]. Tokyo: Kadokawa Shoten.

Bairon, Fija, Matthias Brenzinger \& Patrick Heinrich. 2009. The Ryukyus and the new, but endangered, languages of Japan. The Asia-Pacific Journal 7(19). 3138.

Beck, David. 2018. Ideophones, adverbs, and predicate qualification in upper Necaxa Totonac. International Journal of American Linguistics 74(1). 1-46.

Benjamini, Yoav \& Yosef Hochberg. 1995. Controlling the false discovery rate: A practical and powerful approach to multiple testing. Journal of the Royal Statistical Society Series B 57. 289-300.

Berlin, Brent \& Paul Kay. 1969. Basic color terms: Their universality and evolution. Berkeley, Los Angeles \& Oxford: University of California Press.

Blench, Roger. 2010. The sensory world: Ideophones in Africa and elsewhere. In Anne Storch (ed.), Perception of the invisible: Religion, historical semantics and the role of perceptive verbs, 275-96. Cologne: Köppe.

Bradshaw, Joel. 2006. Grammatically marked ideophones in Numbami and Jabem. Oceanic Linguistics 45(1). 53-63.

Calvert, Gemma A., Charles Spence \& Barry E. Stein. 2004. The handbook of multisensory processing. Cambridge, MA: MIT Press.

Childs, G Tucker. 2001. Research on ideophones, whither hence? The need for a social theory of ideophones. Typological Studies in Language 44. 63-74.

Csardi, Gabor \& Tamas Nepusz. 2006. The igraph software package for complex network research. InterJournal, Complex Systems 1695(5). 1-9.

Diatka, Vojtěch. 2014. Hindi ideophones. Prague: Karlova University MA thesis. 
Diffloth, Gérard. 1972. Notes on expressive meaning. Chicago Linguistic Society 8(44). 440-447.

Diffloth, Gérard. 1976. Expressives in Semai. Oceanic Linguistics Special Publications 13. 249-264.

Dingemanse, Mark. 2011a. Ideophones and the aesthetics of everyday language in a West-African society. The Senses and Society 6(1). 77-85.

Dingemanse, Mark. 2011b. The meaning and use of ideophones in Siwu. Nijmegen: Radboud University PhD thesis.

Dingemanse, Mark. 2012. Advances in the cross-linguistic study of ideophones. Language and Linguistics Compass 6(10). 654-672.

Dingemanse, Mark. 2014. Making new ideophones in Siwu: Creative depiction in conversation. Pragmatics and Society 5(3). 384-405.

Dingemanse, Mark. 2019. "Ideophone" as a comparative concept. In Kimi Akita \& Prashant Pardeshi (eds.), Ideophones, mimetics, and expressives, 13-33. Amsterdam: John Benjamins Publishing Company.

Dingemanse, Mark \& Asifa Majid. 2012. The semantic structure of sensory vocabulary in an African language. In Proceedings of the 34th Annual Conference of the Cognitive Science Society, 300-305.

Döhler, Christian. 2018. A grammar of Komnzo (Studies in Diversity Linguistics). Berlin: Language Science Press.

Edward, Mary. 2015. We speak with our hands and voices: Iconicity in the Adamorobe Sign Language and the Akuapem Twi (ideophones). University of Bergen MA thesis.

Egbokhare, Francis 0. 2001. Phonosemantic correspondences in Emai attributive ideophones. In F. K. Erhard Voeltz \& Christa Kilian-Hatz (eds.), Ideophones, 87-96. Philadelphia: John Benjamins Publishing Company.

Fidler, Masako U. 2019. The power of "not saying who" in Czech onomatopoeia. In Kimi Akita \& Prashant Pardeshi (eds.), Ideophones, mimetics and expressives (Iconicity in Language and Literature), vol. 16, 199-227. London \& New York: John Benjamins Publishing Company.

Fortune, George. 1962. Ideophones in Shona. London: Oxford University Press.

Fu, Kai-Ming G., Taylor A. Johnston, Ankoor S. Shah, Lori Arnold, John Smiley, Troy A. Hackett, Preston E. Garraghty \& Charles E. Schroeder. 2003. Auditory cortical neurons respond to somatosensory stimulation. Journal of Neuroscience 23(20). 7510-7515.

Fukushima, Hiroki, Mutsumi Imai \& Shigenori Tanaka. 2017. The usage mechanism of Japanese ideophones in the description of taste: Morphological and co-occurrence analysis of the description of wines and sakes. International Journal of Computational Linguistics Research 8(3). 109-122.

Gomi, Taro. 1989. An illustrated dictionary of Japanese onomatopoeic expressions. Tokyo: The Japan Times.

Goodman, Nelson. 1968. Languages of art: An approach to the theory of symbols. Indianapolis: Bobbs-Merrill.

Hamano, Shoko. 1998. The sound-symbolic system of Japanese. Stanford: CSLI Publications.

Haspelmath, Martin. 2003. The geometry of grammatical meaning: Semantic maps and crosslinguistic comparison. In Michael Tomasello (ed.), The new psychology of language, vol. 2, 211-242. Mahwah, NJ: Lawrence Erlbaum.

Hayakawa, Fumiyo, Keiko Hatae \& Atsuko Shimada. 2000. Shoku kankaku-no giongo gitaigo-no tokuchō-duke [Characterisation of onomatopoeic terms for describing food properties]. Nippon Shokuhin Kagaku Kogaku Kaisi 47(3). 197-207. 
Hinton, Leanne, Johanna Nichols \& John J. Ohala. 1994. Sound symbolism. Cambridge: Cambridge University Press.

Hothorn, Torsten, Kurt Hornik \& Achim Zeileis. 2006. Unbiased recursive partitioning: A conditional inference framework. Journal of Computational and Graphical Statistics 15(3). 651-674.

Hsiao, Steven S. \& Sliman Bensmaia. 2008. Coding of object shape and texture. In Richard H. Masland et al. (ed.), The senses: A comprehensive reference, 55-66. Cambridge, Massachusetts: Elsevier Inc.

Huisman, John L.A., Asifa Majid \& Roeland Van Hout. 2019. The geographical configuration of a language area influences linguistic diversity. PLoS One 14(6). e0217363.

Ibarretxe-Antuñano, Iraide. 2019. Towards a semantic typological classification of motion ideophones. In Kimi Akita \& Prashant Pardeshi (eds.), Ideophones, mimetics and expressives (Iconicity in Language and Literature 16), 137-166. Amsterdam \& Philadelphia: John Benjamins Publishing Company.

Iwasaki, Noriko, Peter Sells \& Kimi Akita (eds.). 2017. The grammar of Japanese mimetics: Perspectives from structure, acquisition, and translation. London \& New York: Routledge.

Izumi, Kunihisa. 1976. Giseigo/gitaigo-no tokushitsu [Some characteristics of mimetics]. In Takao Suzuki (ed.), Nihongo-no goi-to hyoogen [Japanese vocabulary and expressions]. Tokyo: Taishukan.

Kakehi, Hisao, Ikuhiro Tamori \& Lawrence Schourp. 1996. Dictionary of iconic expressions in Japanese. Berlin: Mouton de Gruyter.

Kaufman, Terrence. 1994. Symbolism and change in the sound system of Huastec. In Leanne Hinton, Johanna Nichols \& John J. Ohala (eds.), Sound symbolism, 63-75. Cambridge: Cambridge University Press.

Kawagoe, Megumi. 2012. Form and meaning of onomatopoeia in Tohoku dialect. Tohoku University PhD thesis.

Kawaguchi, Yuji \& Fumio Inoue. 2002. Japanese dialectology in historical perspectives. Revue Belge de Philologie et d'Histoire 80(3). 801-829.

Kilian-Hatz, Christa. 2001. Universality and diversality: Ideophones from Baka and Kxoe. In Erhard F. K. Voeltz \& Christa Kilian-Hatz (eds.), Ideophones (Typological Studies in Language), vol. 44. Amsterdam and Philadelphia: John Benjamins Publishing Company.

Klatzky, Roberta L. \& Susan J. Lederman. 2010. Multisensory texture perception. In Jochen Kaiser \& Marcus J.Naumer (eds.), Multisensory object perception in the primate brain, 211-230. New York: Springer.

Kuznetsova, Alexandra, Per B. Brockhoff \& Rune H. B. Christensen. 2017. ImerTest Package: Tests in linear mixed effects models. Journal of Statistical Software 82(13). (22 April, 2020).

Lee, Sean \& Toshikazu Hasegawa. 2011. Bayesian phylogenetic analysis supports an agricultural origin of Japonic languages. In Proceedings of the Royal Society of London B: Biological Sciences rspb20110518.

Levinson, Stephen \& Sérgio Meira. 2003. "Natural concepts" in the spatial topological domainAdpositional meanings in crosslinguistic perspective: An exercise in semantic typology. Language 79(3). 485-516.

Livingstone, Margaret \& David Hubel. 1988. Segregation of form, color, movement, and depth: Anatomy, physiology, and perception. Science 240(4853). 740-749.

Lupyan, Gary \& Bodo Winter. 2018. Language is more abstract than you think, or, why aren't languages more iconic? Philosophical Transactions of the Royal Society B: Biological Sciences 373(1752). 20170137. 
Majid, Asifa. 2012. A guide to stimulus-based elicitation for semantic categories. In Nicholas Thieberger (ed.). The Oxford handbook of linguistic fieldwork, 54-71. Oxford: Oxford University Press.

Majid, Asifa, James S. Boster \& Melissa Bowerman. 2008. The cross-linguistic categorization of everyday events: A study of cutting and breaking. Cognition 109(2). 235-250.

Majid, Asifa, Seán G. Roberts, Ludy Cilissen, Karen Emmorey, Brenda Nicodemus, Lucinda O'Grady, Bencie Woll, Barbara LeLan, Hilário De Sousa \& Brian L. Cansler. 2018. Differential coding of perception in the world's languages. Proceedings of the National Academy of Sciences of the United States of America 115(45). 11369-11376.

Marks, Lawrence E. 1978. The unity of the senses: Interrelations among the modalities. New York \& London: Academic Press.

Morikawa, I. 2002. Onomatope-no noonai-shori-ni tsuite: Shinkei-shinrigakuteki-apuroochi [On brain mapping of onomatopoeia]. Kobe University MA thesis.

Nakagawa, Hirosi. 2011. A first report on G| Ui ideophones. In Osamu Hieda, Christa Konig \& Hirosi Nakagawa (eds.), Geographical typology and linguistic areas: With special reference to Africa (Tokyo University of Foreign Studies in Linguistics 2), 279-286. Amsterdam \& Philadelphia: John Benjamins Publishing Company.

Nakagawa, Hirosi. 2013. G| ui ideophones: Work in progress. Asian and African Languages and Linguistics 8. 99-121.

Nakazato, Michiko. 2002. Polysemy and change in the meanings of onomatopoeia: In the case of majimaji. Jōetsukyōikudaigaku kenkyū kiyō 22(1). 282-268.

Nakazato, Michiko. 2004a. Onomatope-no imi shukushō: Wakuwaku-o rei-ni [Meaning reduction in onomatopoeia: The case of wakuwaku]. Jōetsukyōikudaigaku kenkyū kiyō 23(2). 842-830.

Nakazato, Michiko. 2004b. Naku namida o byōsha suru onomatope no hensen: Chūko kara kindai ni kakete [Changes in onomatopoeia of crying and tears from the Heian period to modern times]. Jōetsukyōikudaigaku kenkyū kiyō 24(1). 316-303.

National Institute for Japanese Language \& Linguistics (NINJAL). 2001. Zenkoku hoogen danwa deetabeesu: nihon-no furusato kotoba shuusei [National database of dialect discourse: $A$ collection of Japan's local languages]. Tokyo: Kokushokankookai.

Nuckolls, Janis B. 1996. Sounds like life: Sound-symbolic grammar, performance, and cognition in Pastaza Quechua (Oxford Studies in Anthropological Linguistics). Oxford: Oxford University Press.

Nuckolls, Janis B. 2019. The sensori-semantic clustering of ideophonic meaning in Pastaza Quichua. In Kimi Akita \& Prashant Pardeshi (eds.), Ideophones, mimetics and expressives (Iconicity in Language and Literature 16), 167-198. Amsterdam \& Philadelphia: John Benjamins Publishing Company.

Nuckolls, Janis B., Tod D. Swanson, Diana Shelton, Alexander Rice \& Sarah Hatton. 2017. Lexicography in-your-face: The active semantics of Pastaza Quichua ideophones. Canadian Journal of Linguistics/Revue Canadienne de Linguistique. Cambridge University Press 62(2). 154-172.

O'Meara, Carolyn, Susan Smythe Kung \& Asifa Majid. 2019. The challenge of olfactory ideophones: Reconsidering ineffability from the Totonac-Tepehua perspective. International Journal of American Linguistics 85(2). 173-212.

Onishi, Takuichiro. 2010. Mapping Japanese dialects. Dialectologia: Revista Electrònica 137-146. Osada, Toshiki, Madhu Purti \& Nathan Badenoch. 2019. A dictionary of Mundari Expressives. Tokyo: ILCAA. 
R Core Team. 2018. R: A language and environment for statistical computing. Vienna, Austria. Available from: https://www.r-project.org/.

Rhee, Seongha \& Hyun Jung Koo. 2017. Multifaceted gustation: Systematicity and productivity of taste terms in Korean. Terminology International Journal of Theoretical and Applied Issues in Specialized Communication 23(1). 38-65.

San Roque, Lila, Kobin H. Kendrick, Elisabeth Norcliffe, Penelope Brown, Rebecca Defina, Mark Dingemanse, Tyko Dirksmeyer, Nick J. Enfield, Simeon Floyd \& Jeremy Hammond. 2015. Vision verbs dominate in conversation across cultures, but the ranking of non-visual verbs varies. Cognitive Linguistics 26(1). 31-60.

Schroeder, Charles E., Robert W. Lindsley, Colleen Specht, Alvin Marcovici, John F. Smiley \& Daniel C. Javitt. 2001. Somatosensory input to auditory association cortex in the macaque monkey. Journal of Neurophysiology 85(3). 1322-1327.

De Schryver, Gilles-Maurice. 2009. The lexicographic treatment of ideophones in Zulu. Lexikos 19. 34-54.

Schultze-Berndt, Eva. 2001. Ideophone-like characteristics of uninflected predicates in Jaminjung (Australia). In F. K. Erhard Voeltz \& Christa Kilian-Hatz (eds.), Ideophones (Typological Studies in Language 44), 9-24. Philadelphia: John Benjamins Publishing Company.

Styles, Suzy J. \& Lauren Gawne. 2017. When does maluma/takete fail? Two key failures and a metaanalysis suggest that phonology and phonotactics matter. i-Perception 8(4). 204166951772480.

Takeda, Akiko. 2012. Toohoku hoogen onomatope yoorei-shuu [Usage examples of mimetic vocabulary in Tohoku dialects]. Tokyo: Kokuritsu Kokugo Kenkyūjo.

Thompson, Arthur Lewis \& Youngah Do. 2019. Defining iconicity: An articulation-based methodology for explaining the phonological structure of ideophones. Glossa: A Journal of General Linguistics. Ubiquity Press 4(1). 72.

Tokunaga, Akiko. 2013. Geographical distribution of mimetics in Amami-Okinoerabu Island. International Journal of Okinawan Studies 4(1). 13-28.

Tolskaya, Maria. 2011. Ideophones as positive polarity items. Harvard University PhD thesis. (30 March, 2020).

Tufvesson, Sylvia. 2007. Expressives. In Asifa Majid (ed.). Field manual, vol. 10, 53-58. Nijmegen, The Netherlands: Max Planck Institute for Psycholinguistics.

Van Hoey, Thomas \& Chiarung Lu. in prep. A semantic map for ideophones: From an implicational hierarchy to the spinning top model.

Viberg, Åke. 1983. The verbs of perception: A typological study. Linguistics 21(1). 123-162.

Watson, Richard L, F. K. Erhard Voeltz \& Christa Kilian-Hatz. 2001. A comparison of some Southeast Asian ideophones with some African ideophones. In F. K. Erhard Voeltz \& Christa Kilian-Hatz (eds.). Ideophones (Typological Studies in Language 44), 385-406. Amsterdam: John Benjamins Publishing Company.

Winter, Bodo, Marcus Perlman, Lynn K. Perry \& Gary Lupyan. 2017. Which words are most iconic? Interaction Studies 18(3). 443-464.

Yamaguchi, Nakami. 2003. Kurasi-no kotoba: giongitaigo jiten [Words for living: A dictionary of mimetics]. Tokyo: Koodansha.

Yanagita, Kunio. 1930. Kagyuukoo - On the dialectal lexicon of snail. Tokyo: Tokoshoin.

Zaro, Amina. 2013. Ideophones in Oromo. Addis Ababa: Addis Ababa University MA thesis. 